\title{
Total vs. Bioavailable: Determining a Better 25(OH)D Index in Association with Bone Density and Muscle Mass in Postmenopausal Women
}

\author{
Nurdiana Z. Abidin 1,2,*(D) and Soma R. Mitra ${ }^{1}$ (D) \\ 1 School of Biosciences, Faculty of Science and Engineering, University of Nottingham Malaysia, \\ 43500 Semenyih, Selangor, Malaysia; soma.mitra@nottingham.edu.my \\ 2 Lifestyle Science Cluster, Advanced Medical and Dental Institute, Universiti Sains Malaysia, \\ 13200 Kepala Batas, Pulau Pinang, Malaysia \\ * Correspondence: diana.abidin@gmail.com or khyx6nhz@nottingham.edu.my; Tel.: +60-192706303
}

Citation: Abidin, N.Z.; Mitra, S.R. Total vs. Bioavailable: Determining a Better 25(OH)D Index in Association with Bone Density and Muscle Mass in Postmenopausal Women.

Metabolites 2021, 11, 23. https:// dx.doi.org/10.3390/metabo11010023

Received: 5 December 2020 Accepted: 19 December 2020 Published: 31 December 2020

Publisher's Note: MDPI stays neutral with regard to jurisdictional claims in published maps and institutional affiliations.

Copyright: () 2020 by the authors. Licensee MDPI, Basel, Switzerland. This article is an open access article distributed under the terms and conditions of the Creative Commons Attribution (CC BY) license (https: / / creativecommons.org/ licenses/by/4.0/).

\begin{abstract}
The concurrent presence of low bone density (osteopenia/osteoporosis) and low muscle mass (sarcopenia) in older adults has led to the recognition of "osteosarcopenia" (OS) as a singular entity. Vitamin D may play important role in the manifestation of OS, in terms of intake, absorption, and bioavailability. Evidence suggests that bioavailable $25(\mathrm{OH}) \mathrm{D}$ may be a better indicator of Vitamin D compared to total 25(OH)D due to its weak bind to albumin, increasing its 'availability'. The aim of this study was to assess total and bioavailable $25(\mathrm{OH}) \mathrm{D}$ levels in postmenopausal women and to determine their associations to bone density and muscle mass. We assessed body composition, bone density, and 25(OH)D indices of multiethnic, postmenopausal Malaysian women. A significant and negative correlation was found between body fat $\%$ and each index of 25(OH)D. Both bioavailable and total $25(\mathrm{OH}) \mathrm{D}$ were positively correlated with serum calcium and negatively correlated with iPTH(intact parathyroid hormone). VDBP(Vitamin D binding protein) level was significantly correlated with bioavailable $25(\mathrm{OH}) \mathrm{D}$ level, but not with the total $25(\mathrm{OH}) \mathrm{D}$ level. Stepwise regression analysis revealed that bioavailable, but not total, 25(OH)D was significantly correlated to bone density and muscle mass, (where stronger correlation was found with bone density), suggesting its superiority. Nevertheless, the low effect size warrants further studies.
\end{abstract}

Keywords: obesity; osteoporosis; sarcopenia; vitamin D; osteosarcopenic obesity

\section{Introduction}

Studies have found that bone and muscle (and also adipose tissue) are endocrine organs that secrete molecules to communicate and form a cross-talk network with each other, and are regulated through the same musculoskeletal pathways [1]. Aging has been found to be one of the factors that cause disturbance to the mesenchymal stem cells (MSC) lineage commitment (which are precursors for bone, muscle and adipose tissue), and subsequently leading to tissue impairments. The tissue impairments tend to lead to multitude of disorders, namely osteoporosis and sarcopenia. To date, there is emerging evidence showing a close link between these two conditions [2]. The interconnected pathways between muscle and bone have led to the hypothesis that the improvement of one may be beneficial to the other. Therefore, the scientific and medical communities are working hard on studying the interconnectedness between these conditions in order to aid in their prevention and treatment. Recently, it has been suggested that vitamin D, which is an essential nutrient required for optimal absorption of dietary calcium and phosphate, may play a role in the development of osteosarcopenia (OS), where an individual has simultaneous manifestation of low bone density (osteoporosis) and low muscle mass (sarcopenia) at the same time [2]. Therefore, it was hypothesised that increased vitamin D levels may lower the risk of developing the combined disorder. 
To understand the effect of vitamin $\mathrm{D}$ on the combined disorder, it is important to understand the effect of vitamin D on each of its component. Hypovitaminosis D (low vitamin D levels) has been found to be prevalent in people with bone and muscle wasting. Prior studies have shown low vitamin D levels to have adverse effects on the absorption of calcium, bone remodeling, and consequently, bone density [3,4]. Further, low vitamin D levels have also been found to be associated with increased parathyroid hormone, which contributes to the catabolism of bones [5-7]. In the case of muscle mass, studies have shown a significant correlation between vitamin $\mathrm{D}$ receptor polymorphisms and reduced muscle mass and function in older adults [8], suggesting the role of vitamin D in sarcopenia [9]. Among the obese populations, the prevalence of hypovitaminosis D is unfortunately higher than among the people of normal weight. Due to the fat-solubility of the micronutrient, where fat essentially acts as a 'sink', vitamin D levels in obese individuals tend to be much lower. Therefore, obese individuals are generally more susceptible to developing musculoskeletal health disorders due to their low vitamin D levels.

Currently, there are still some controversies regarding the exact role of vitamin D in musculoskeletal health. Studies on the effects of vitamin D on muscle or bone health have shown conflicting results, likely due to the heterogeneity between studies [10,11]. Moreover, due to the design of studies, causality is impossible to determine [12-14]. Therefore, various hypotheses emerged to explain the conflicting results, among which, include the free hormone hypothesis.

\section{Free Hormone Hypothesis: Total vs. Bioavailable 25(OH)D}

Currently, 'total' 25-hydroxyvitamin D $(25(\mathrm{OH}) \mathrm{D})$ is considered to be an indicator of vitamin $\mathrm{D}$ status. This metabolite reflects the overall body storage of the immediate vitamin D precursor that is hydroxylated to active 1,25-dihydroxyvitamin $\mathrm{D}$. In the body, after undergoing the first hydroxylation in the liver, 'total' serum $25(\mathrm{OH}) \mathrm{D}$ is bounded to vitamin D binding protein (VDBP) and Albumin (Alb), which then transported to the kidney and get converted to hormonally active 1,25 -dihydroxyvitamin $\mathrm{D}\left(1,25(\mathrm{OH})_{2} \mathrm{D}\right)$ [15]. In the circulation, most of both $25(\mathrm{OH}) \mathrm{D}$ and $1,25(\mathrm{OH})_{2} \mathrm{D}$ are bounded to VDBP $(\sim 85-90 \%)$, approximately $10-15 \%$ to Alb, and less than $1 \%$ is considered as 'free' and unbounded to anything [16]. Since the affinity of $25(\mathrm{OH}) \mathrm{D}$ or $1,25(\mathrm{OH})_{2} \mathrm{D}$ to Alb is weaker than to VDBP, the loosely bound fraction and the 'free' fraction together make up the 'bioavailable' $25(\mathrm{OH}) \mathrm{D}$ [17]. Free hormone hypothesis posits that the core activity of a hormone may be due to the 'bioavailable' fraction and its passive diffusion across the membrane. In the case of vitamin $\mathrm{D}$, the majority of the vitamin in the blood is bounded to VDBP, rendering it unavailable for passive diffusion. Emerging evidence is showing that bioavailable $25(\mathrm{OH}) \mathrm{D}$ (the fraction that's not bound to VDBP), may be the better indicator of vitamin D status compared to the 'total' 25(OH)D (aka the free hormone hypothesis) [18,19].

Currently, there are contradicting findings on the correlation of total $25(\mathrm{OH}) \mathrm{D}$ with bone density and muscle mass. Studies suggest that bioavailable fraction of $25(\mathrm{OH}) \mathrm{D}$ may be a better indicator for vitamin $\mathrm{D}$ status than total $25(\mathrm{OH}) \mathrm{D}$ in relation to musculoskeletal health. For example, a study by Lowe et al. [20] which investigated the differences in vitamin D status in postmenopausal South Asian and Caucasian women in the UK and its relationship to parathyroid hormone (PTH) concentration, biochemical markers of bone turnover and bone quality, found that although the South Asian women had significantly lower total 25(OH)D concentrations and higher serum PTH than the Caucasian women, they were not associated with significantly higher markers of bone resorption, or reduced bone quality. These findings suggest that factors other than just the level of total $25(\mathrm{OH}) \mathrm{D}$ might play a role in bone quality and health, which, based on various studies $[19,21]$, are likely to be the bioavailable fraction of $25(\mathrm{OH}) \mathrm{D}$. Perhaps the measurement of bioavailable $25(\mathrm{OH}) \mathrm{D}$ may need to be incorporated into the routine assessment to improve the determination of vitamin $\mathrm{D}$ status in diverse populations.

To the best of our knowledge, very few studies were designed to assess bioavailable vitamin D status and its correlation to musculoskeletal health in community-dwelling 
postmenopausal women. Therefore, the aim of the current study was to assess the status of total and bioavailable $25(\mathrm{OH}) \mathrm{D}$ in community-dwelling postmenopausal women and determined if the bioavailable fraction of $25(\mathrm{OH}) \mathrm{D}$ is the better biochemical indicator for vitamin $\mathrm{D}$ status than total $25(\mathrm{OH}) \mathrm{D}$ in relation to muscle mass and bone density.

\section{Results}

Table 1 shows the characteristics and body composition measurement of participants. Median and interquartile range (IQR) of age, age at menopause, and years since menopause are 59.0(10.0) years, 50.0(6.0) years and 8.0(11.0) years, respectively. Categorization based on BMI shows that the prevalence of 'Obesity' (BMI $\geq 27.5 \mathrm{~kg} / \mathrm{m}^{2}$ ) was $48.0 \%$ $(n=68)$. Alternatively, if categorization was based on waist circumference (WC) and body fat percent (BFP), the proportion for Obese/Overweight were $63.0 \%(n=87)$ and $86.0 \%$ $(n=121)$, respectively.

Table 1. Characteristics (Malay, $n=51$; Chinese, $n=42$; Indian, $n=48$ ) and blood parameters (Malay, $n=49$; Chinese, $n=35$; Indian, $n=36$ ) of participants.

\begin{tabular}{|c|c|c|c|c|c|}
\hline Variables & & Reference & $N$ & $\begin{array}{c}\text { Mean } \pm \text { SD/Median } \\
(\text { IQR) }\end{array}$ & $\begin{array}{l}\text { Minimum- } \\
\text { Maximum }\end{array}$ \\
\hline Age (years) & & & 141 & $59.0(10.0)$ & $45.0-88.0$ \\
\hline Age at menopause (years) & & & 121 & $50.0(6.0)$ & $36.0-59.0$ \\
\hline Years since menopause & & & 121 & 8.0(11.0) & $1.0-35.0$ \\
\hline Height $(\mathrm{cm})$ & & & 141 & $153.1 \pm 6.2$ & $137.5-169.0$ \\
\hline Weight (kg) & & & 141 & $63.4 \pm 12.6$ & $31.9-100.9$ \\
\hline \multirow{4}{*}{ BMI $\left(\mathrm{kg} / \mathrm{m}^{2}\right)^{\delta}$} & All & & 141 & $27.1 \pm 5.3$ & $15.4-43.0$ \\
\hline & Normal & $18.5-22.99$ & 29 & $20.8 \pm 1.3$ & $18.5-22.8$ \\
\hline & Overweight & $23.0-27.49$ & 40 & $25.0(2.65)$ & $23.1-27.4$ \\
\hline & Obese Type 1 and 2 & $\geq 27.5$ & 68 & $30.25(4.1)$ & $27.5-43.0$ \\
\hline \multirow[t]{2}{*}{ Waist circ. $(\mathrm{cm})^{\mu}$} & All & & 139 & $84.2 \pm 12.6$ & $55.1-121.0$ \\
\hline & Overweight/Obese & $\geq 80 \mathrm{~cm}$ & 87 & $89.7(11.2)$ & $80.0-121.0$ \\
\hline \multirow[t]{2}{*}{ Body fat (\%) } & All & & 141 & $41.8(10.45)$ & $20.7-54.0$ \\
\hline & Obese $^{\gamma}$ & $\geq 32 \%$ & 121 & $43.1(8.8)$ & $32.3-54.0$ \\
\hline \multirow[t]{2}{*}{$\operatorname{AppSMMI}\left(\mathrm{kg} / \mathrm{m}^{2}\right)$} & All & & 140 & $6.1(1.1)$ & $4.0-10.7$ \\
\hline & Sarcopenic $\beta$ & $\leq 5.7 \mathrm{~kg} / \mathrm{m}^{2}$ & 44 & $5.3(0.4)$ & $4.01-5.69$ \\
\hline \multirow[t]{2}{*}{$\mathrm{BUA}(\mathrm{dB} / \mathrm{MHz})$} & All & & 139 & $70.0 \pm 16.8$ & $35.9-122.2$ \\
\hline & Osteopenic ${ }^{\alpha}$ & $<54 \mathrm{~dB} / \mathrm{MHz}$ & 25 & $47.5(9.75)$ & $35.9-53.8$ \\
\hline Total 25(OH)D (nmol/L) ${ }^{f}$ & & $>50 \mathrm{nmol} / \mathrm{L}$ & 120 & $51.0(23.85)$ & $23.0-117.6$ \\
\hline Serum Calcium $(\mathrm{mmol} / \mathrm{L})^{t}$ & & $2.10-2.55 \mathrm{mmol} / \mathrm{L}$ & 120 & $2.4 \pm 0.1$ & $2.15-2.65$ \\
\hline Plasma iPTH $(\mathrm{pmol} / \mathrm{L})^{t}$ & & $1.5-7.6 \mathrm{pmol} / \mathrm{L}$ & 119 & $5.2(3.7)$ & $1.60-12.30$ \\
\hline Serum albumin $(\mathrm{g} / \mathrm{L})^{\mathrm{t}}$ & & $35-50 \mathrm{~g} / \mathrm{L}$ & 120 & $45.0(5.0)$ & $38.0-50.0$ \\
\hline Bioavailable 25(OH)D (nmol/L) & & & 116 & $6.2(3.2)$ & $2.83-17.0$ \\
\hline Bioavailable 25(OH)D (ng/mL $)^{t}$ & & $1.92-8.82 \mathrm{ng} / \mathrm{mL}$ & 116 & $2.5(1.3)$ & $1.13-6.80$ \\
\hline Free $25(\mathrm{OH}) \mathrm{D}(\mathrm{pmol} / \mathrm{L})$ & & & 116 & $15.7(7.4)$ & $6.87-43.2$ \\
\hline $\operatorname{VDBP}(\mathrm{ug} / \mathrm{mL})^{t}$ & & $104-477 \mathrm{ug} / \mathrm{mL}$ & 116 & $224.7 \pm 44.8$ & $123.5-327.7$ \\
\hline
\end{tabular}

N.B: appSMMI = appendicular skeletal muscle mass index, BMI = body mass index, four participants $(n=4)$ were underweight $\mathrm{BMI}<18.5 \mathrm{~kg} / \mathrm{m}^{2}$, BUA = broadband ultrasonic attenuation, $\mathrm{SD}=$ standard deviation, iPTH $=$ intact parathyroid hormone, $\mathrm{IQR}=$ interquartile range, $\mathrm{VDBP}=$ vitamin $\mathrm{D}$ binding protein, $25(\mathrm{OH}) \mathrm{D}=25$-hydroxyvitamin $\mathrm{D},{ }^{\delta}=\mathrm{WHO}, 2004[22], \mu=\mathrm{WHO}, 2008[23]$, $\gamma=$ Ilich et al., 2016 [24], ${ }^{\beta}=$ AWGS [25], ${ }^{\alpha}=$ Johansen, Evans \& Stone, 1999 [26], ${ }^{f}=$ based on cut-points by IOM (Institute of Medicine) Dietary Reference Intakes for Calcium and Vitamin D. Washington, DC: The National Academies Press; 2011 [27], ${ }^{\ddagger}$ Pan Laboratories, Irvine, USA reference range for adults, http:/ / panlaboratories.com/bioavailable-vitamin-d-25-hydroxy/which were based on previous studies $[19,21,28]$.

According to the standard cut-off based on appendicular skeletal muscle mass index (appSMMI) $\leq 5.7 \mathrm{~kg} / \mathrm{m}^{2}$ [25], the prevalence for sarcopenia was $31.2 \%(n=44)$. Based on the standard cut-off for broadband ultrasonic attenuation (BUA $<54 \mathrm{~dB} / \mathrm{MHz}$ ) [26], the prevalence for osteopenic/osteoporosis was 18.0\% $(n=25)$. The median and IQR of total, bioavailable and free $25(\mathrm{OH}) \mathrm{D}$ were $51.0(23.85) \mathrm{nmol} / \mathrm{L}, 6.2(3.2) \mathrm{nmol} / \mathrm{L}$, and $15.7(7.4)$ 
pmol/L, respectively. The results for each blood parameter were all within the normal range for adults.

Background information such as education level, smoking habit, alcohol-drinking habit, physical activity level and co-morbidities were collected from postmenopausal women using a questionnaire (Table 2). The current study found that a majority of the participants were educated at the secondary school level or higher $(77.0 \%)$, non-cigarette smoking (98.6\%), and non-alcohol drinking (97.8\%) individuals. Half of the cohort (50.4\%) reported to be 'inactive' during the week while the other half reported to have some amount of physical activity (other than regular types of activity such as household chores) at least 10 min per day. Forty-three percent (43.2\%) of participants reported to not have or ever have been diagnosed with any type of disorders listed in the questionnaire.

Table 2. The demographic data of study participants.

\begin{tabular}{|c|c|c|c|c|}
\hline Variables & N Total & Breakdown of variables & $n$ & Percentage $(\%)$ \\
\hline \multirow[t]{6}{*}{ Education Levels } & 140 & No Formal Education & 10 & 7.1 \\
\hline & & Primary School & 22 & 15.7 \\
\hline & & Secondary School & 55 & 39.3 \\
\hline & & Certificate/Diploma & 29 & 20.7 \\
\hline & & University Degree & 19 & 13.6 \\
\hline & & Postgraduate Degree & 5 & 3.6 \\
\hline \multirow[t]{2}{*}{ Cigarette Smoking Status } & 139 & Non-smoker & 137 & 98.6 \\
\hline & & Current smoker & 2 & 1.4 \\
\hline \multirow[t]{2}{*}{ Alcohol Drinking } & 138 & Non-drinker & 136 & 97.8 \\
\hline & & Current drinker & 2 & 2.2 \\
\hline \multirow[t]{2}{*}{ Self-rated PA Status } & 137 & Inactive & 69 & 50.4 \\
\hline & & Active (at least 10 mins per day) & 68 & 49.6 \\
\hline \multirow[t]{9}{*}{ Disease(s)/disorder(s) } & 139 & None & 60 & 43.2 \\
\hline & & Hypertension & 53 & \\
\hline & & Diabetes Type 2 & 31 & \\
\hline & & Heart problems & 11 & \\
\hline & & Osteoarthritis & 12 & \\
\hline & & Rheumatoid Arthritis & 7 & \\
\hline & & Osteoporosis & 8 & \\
\hline & & Have had stroke & 4 & \\
\hline & & Depression/anxiety & 6 & \\
\hline
\end{tabular}

N.B: PA = physical activity.

Table 3 describes the characteristics of people with different statuses of vitamin D; deficient, insufficient, and replete. The majority of participants in this cohort were in the 'vitamin D replete' category $(51.7 \%,>50 \mathrm{nmol} / \mathrm{L})$, followed by 'vitamin D insufficient' (40.8\%, 30-50 nmol/L) and 'vitamin D deficient' (7.5\%, <30 nmol/L).

Results shows that participants with lower levels of vitamin D (deficient and insufficient groups) had significantly higher iPTH, body fat percent (BFP) ( $p$-value $<0.05)$, and lower free and bioavailable $25(\mathrm{OH}) \mathrm{D}(p$-value $<0.001)$ compared to participants with higher levels of vitamin D (replete group). Additionally, participants in the 'deficient' group had significantly lower bone density (BUA) and blood serum calcium level compared to the group with higher levels of vitamin D (replete) ( $p$-value $<0.05)$. There were no significant differences of variables between 'deficient' and 'insufficient' groups except for bioavailable and free $25(\mathrm{OH}) \mathrm{D}$ ( $p$-value $<0.05)$.

With regard to functional performance, participants with lower levels of vitamin D (deficient and insufficient) were found to have significantly lower endurance (walk speed) compared to participants with higher levels of vitamin D (replete, $p$-value $<0.01$ ). No significant differences, however, were found for lower extremity strength (sit-to-stand test) and balance between the groups. There were also no significant differences found for any of the muscle indices, handgrip strength (HGS) and VDBP between the groups. 
Table 3. The differences in characteristics for participants who were Vitamin D (Total 25(OH)D) deficient, insufficient, and replete.

\begin{tabular}{|c|c|c|c|c|}
\hline Variables & $\begin{array}{l}\text { Deficient }(<30 \mathrm{nmol} / \mathrm{L})^{f} \\
\text { Mean (SD), } n=9\end{array}$ & $\begin{array}{c}\text { Insufficient }(30-50 \mathrm{nmol} / \mathrm{L})^{f} \\
\text { Mean (SD), } n=49\end{array}$ & $\begin{array}{l}\text { Replete }(>50 \mathrm{nmol} / \mathrm{L})^{f} \\
\text { Mean (SD), } n=62\end{array}$ & $p$-Value * \\
\hline HGS $(\mathrm{kg})$ & $20.7(5.5)$ & $18.7(4.7)$ & $20.8(4.6)$ & 0.091 \\
\hline $\operatorname{AppSMMI}\left(\mathrm{kg} / \mathrm{m}^{2}\right)$ & $6.0(1.3)$ & $6.1(0.8)$ & $6.1(0.7)$ & 0.978 \\
\hline SMMI (kg) & $8.7(1.5)$ & $8.4(1.0)$ & $8.4(0.9)$ & 0.822 \\
\hline FFMI (kg) & $16.3(2.3)$ & $15.8(1.6)$ & $15.7(1.5)$ & 0.695 \\
\hline BFP $(\%)$ & $43.6(9.8)^{* *}$ & $43.1(6.7)^{* *}$ & $38.8(8.1)$ & 0.020 \\
\hline $\operatorname{BMI}\left(\mathrm{kg} / \mathrm{m}^{2}\right)$ & $29.9(7.5)$ & $28.3(5.5)$ & $26.1(4.9)$ & 0.073 \\
\hline $\mathrm{WC}(\mathrm{cm})$ & $89.0(14.8)$ & $84.6(12.6)$ & $83.9(12.4)$ & 0.625 \\
\hline BUA $(\mathrm{dB} / \mathrm{MHz})$ & $56.5(16.6) * *$ & $68.5(15.8)$ & $72.2(17.4)$ & 0.047 \\
\hline Sit-to-stand test (times in $30 \mathrm{~s}$ ) & $11.8(2.6)$ & $11.1(3.7)$ & $12.4(3.6)$ & 0.213 \\
\hline Walk speed $(\mathrm{m} / \mathrm{s})$ & $0.7(0.2)^{* *}$ & $0.9(0.2) * *$ & $1.0(0.3)$ & 0.010 \\
\hline Balance (sec) & $17.9(11.7)$ & $17.3(11.8)$ & $21.3(9.8)$ & 0.200 \\
\hline Calcium (mmol/L) & $2.3(0.1)^{* *}$ & $2.4(0.1)$ & $2.4(0.1)$ & 0.015 \\
\hline iPTH $(\mathrm{pmol} / \mathrm{L})$ & $9.1(3.1)^{* *}$ & $6.7(2.5) * *$ & $4.7(2.2)$ & 0.000 \\
\hline $\begin{array}{c}\text { Bioavailable 25(OH)D } \\
(\mathrm{nmol} / \mathrm{L})\end{array}$ & $3.6(0.6)^{* * \#}$ & $5.3(1.2)^{* *}$ & $8.8(3.0)$ & 0.000 \\
\hline Free $25(\mathrm{OH}) \mathrm{D}(\mathrm{pmol} / \mathrm{L})$ & $9.2(1.6)^{* * \#}$ & $13.2(3.1)^{* *}$ & $22.0(7.0)$ & 0.000 \\
\hline VDBP (ug/mL) & $206.1(36.8)$ & $227.1(48.3)$ & $225.6(43.0)$ & 0.328 \\
\hline
\end{tabular}

N.B: appSMMI = appendicular skeletal muscle mass index, $\mathrm{BFP}=$ body fat percent, $\mathrm{BUA}=$ Broadband ultrasonic attenuation, $\mathrm{FFMI}=$ fat free mass index, HGS = handgrip strength, $\mathrm{iPTH}=$ intact parathyroid hormone, $\mathrm{SD}=$ standard deviation, $\mathrm{SMMI}=$ skeletal muscle mass index, $\mathrm{WC}=$ waist circumference, $\mathrm{VDBP}=$ vitamin $\mathrm{D}$ binding protein, $25(\mathrm{OH}) \mathrm{D}=25$-hydroxyvitamin $\mathrm{D}, f=$ based on cut-points by $\mathrm{IOM}$ (Institute of Medicine) Dietary Reference Intakes for Calcium and Vitamin D. Washington, DC: The National Academies Press; 2011 [27], * analysed using one-way ANOVA (Welch Test) with Games-Howell Post-hoc test, $p$-value $\leq 0.05$ (indicated in bold), ** $=$ different from Replete, \# = different from Insufficient.

Figure 1 shows ethnic differences between Malaysian-Malays, Malaysian-Chinese and Malaysian-Indians for 25(OH)D indices (total, free and bioavailable 25(OH)D), body fat percentage and serum calcium levels.

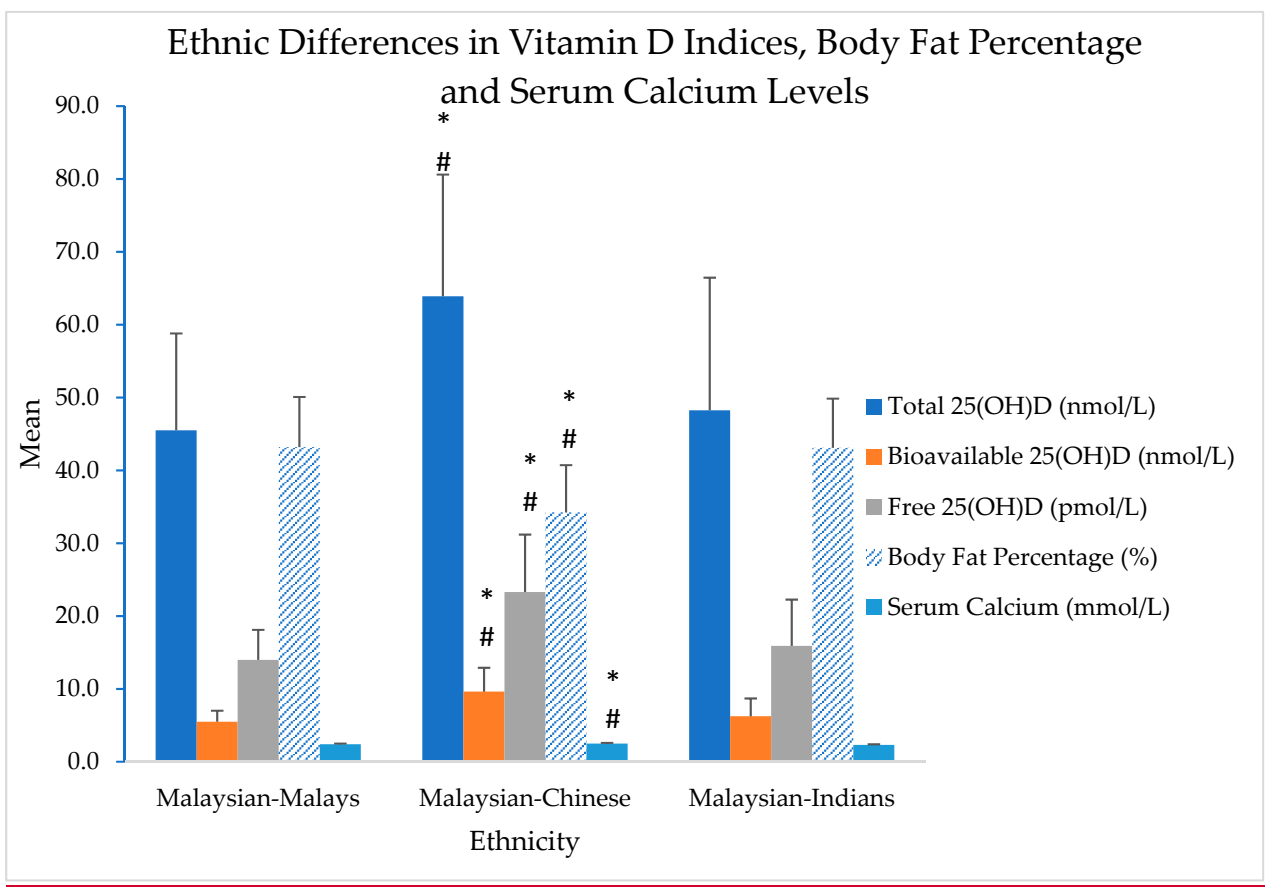

Figure 1. 25(OH)D indices, body fat percentage and serum calcium levels according to ethnicity; Malaysian-Malays, $n=49$, Malaysian-Chinese, $n=35$, Malaysian-Indians $=36$. Error bars: +1 Standard deviation, ${ }^{*}$ analysed using one-way ANOVA, with Tukey's HSD Post-hoc test, \# = different from Malaysian-Malays and Malaysian-Indians, $p$-value $<0.001$. 
Results shows that Malaysian-Chinese had significantly higher levels of serum calcium, total, free and bioavailable $25(\mathrm{OH}) \mathrm{D}$, and significantly lower body fat percentage compared to Malaysian-Malays and Malaysian-Indians ( $p$-value < 0.05). Although there were slight variations in the levels of vitamin D indices between the Malaysian-Malays and MalaysianIndians (Malaysian-Indians > Malaysian-Malays), no statistical significance was found.

Table 4 shows the correlations of blood biomarkers with fat, bone, muscle, and functional performance.

Table 4. Pearson's correlation coefficient of blood biomarkers with fat, bone, muscle, and functional performance.

\begin{tabular}{|c|c|c|c|c|c|c|c|c|c|c|}
\hline Parameters & $\begin{array}{c}\text { Total } \\
25(\mathrm{OH}) \mathrm{D} \\
(\mathrm{nmol} / \mathrm{L})\end{array}$ & \begin{tabular}{c}
\multicolumn{1}{c}{ Bio } \\
25(OH)D \\
$(\mathrm{nmol} / \mathrm{L})$
\end{tabular} & $\begin{array}{l}\text { VDBP } \\
\text { (ug/mL) }\end{array}$ & $\begin{array}{l}\text { Calcium } \\
(\mathrm{mmol} / \mathrm{L})\end{array}$ & $\begin{array}{c}\text { iPTH } \\
(\mathrm{pmol} / \mathrm{L})\end{array}$ & BFP (\%) & $\begin{array}{c}\text { BUA } \\
\text { (dB/MHz) }\end{array}$ & $\begin{array}{l}\operatorname{AppSMMI} \\
\left(\mathrm{kg} / \mathrm{m}^{2}\right)\end{array}$ & STS & $\mathrm{GS}(\mathrm{m} / \mathrm{s})$ \\
\hline $\begin{array}{c}\text { Total } \\
25(\mathrm{OH}) \mathrm{D}\end{array}$ & 1 & $0.883^{* *}$ & -0.045 & $0.192^{*}$ & $-0.394^{* *}$ & $-0.298^{* *}$ & 0.199 * & 0.012 & 0.129 & 0.191 * \\
\hline $\begin{array}{c}\text { Bio } \\
\text { 25(OH)D }\end{array}$ & $0.883^{* *}$ & 1 & $-0.446^{* *}$ & $0.238^{*}$ & $-0.426^{* *}$ & $-0.380^{* *}$ & 0.234 * & -0.007 & 0.202 * & 0.134 \\
\hline VDBP & -0.045 & $-0.446^{* *}$ & 1 & 0.123 & 0.071 & 0.149 & -0.080 & 0.124 & 0.002 & -0.115 \\
\hline Calcium & $0.192 *$ & $0.238 *$ & 0.123 & 1 & $-0.497^{* *}$ & $-0.294^{* *}$ & 0.072 & -0.170 & 0.164 & 0.045 \\
\hline iPTH & $-0.394^{* *}$ & $-0.426^{* *}$ & 0.071 & $-0.497^{* *}$ & 1 & $0.448^{* *}$ & -0.117 & $0.241^{* *}$ & $-0.249^{* *}$ & -0.067 \\
\hline BFP & $-0.298^{* *}$ & $-0.380^{* *}$ & 0.149 & $-0.294^{* *}$ & $0.448^{* *}$ & 1 & 0.043 & $0.359 * *$ & $-0.198 *$ & -0.046 \\
\hline BUA & $0.199^{*}$ & 0.234 * & -0.080 & 0.072 & -0.117 & 0.043 & 1 & $0.192 *$ & 0.143 & 0.050 \\
\hline AppSMMI & 0.012 & -0.007 & 0.124 & -0.170 & $0.241^{* *}$ & $0.359 * *$ & 0.192 * & 1 & 0.011 & $0.248^{* *}$ \\
\hline STS & 0.129 & 0.202 * & 0.002 & 0.164 & $-0.249^{* *}$ & $-0.198 *$ & 0.143 & 0.011 & 1 & $0.350 * *$ \\
\hline GS & 0.191 * & 0.134 & -0.115 & 0.045 & -0.067 & -0.046 & 0.050 & $0.248^{* *}$ & $0.350^{* *}$ & 1 \\
\hline
\end{tabular}

N.B: appSMMI = appendicular skeletal muscle mass index, BUA = broadband ultrasonic attenuation, $\mathrm{BFP}=$ body fat percent, GS = gait speed, $\mathrm{iPTH}=$ intact parathyroid hormone, $\mathrm{STS}=$ sit-to-stand, $\mathrm{VDBP}=$ vitamin $\mathrm{D}$ binding protein, $25(\mathrm{OH}) \mathrm{D}=25$-hydroxyvitamin $\mathrm{D}$, $* p$-value $<0.05, * * p$-value $<0.01$.

The current study found that each form of $25(\mathrm{OH}) \mathrm{D}$ (total and bioavailable) was negatively correlated with body fat percent (BFP) $(r=-0.298, r=-0.380$, respectively, $p$-value $<0.05)$ and positively correlated with bone density, BUA dB/MHz $(r=0.199$, $r=0.234$, respectively, $p$-value $<0.05)$. With regards to functional performance, gait speed (GS) was found to be positively correlated to total 25(OH)D $(r=0.191$, $p$-value $<0.05)$, while lower extremity strength (STS) was found to be positively correlated with bioavailable $25(\mathrm{OH}) \mathrm{D}(r=0.202, p$-value $<0.05)$. Both forms of $25(\mathrm{OH}) \mathrm{D}$ (total and bioavailable) were positively correlated with Calcium $(p$-value $<0.05)$ and negatively correlated with iPTH $(p$-value $<0.01)$.

There were no significant correlations, however, between total and bioavailable 25(OH)D and muscle mass (appSMMI).

To determine the extent to which the $25(\mathrm{OH}) \mathrm{D}$ indices are responsible for the variations in the bone density (BUA dB/MHz) and muscle mass (appSMMI $\mathrm{kg} / \mathrm{m}^{2}$ ) values, stepwise regression analyses were conducted (Table 5). In this analysis, the variables entered were: age, years since menopause, BMI, BFP, total $25(\mathrm{OH}) \mathrm{D}$, bioavailable $25(\mathrm{OH}) \mathrm{D}$, and free $25(\mathrm{OH}) \mathrm{D}$. For bone density, only age and bioavailable $25(\mathrm{OH}) \mathrm{D}$ were significant and explained $7.2 \%$ of the variance. For muscle mass, only BMI, BFP and bioavailable 25(OH)D were significant and explained $64.0 \%$ of the variance. 
Table 5. Stepwise regression analyses of vitamin D indices with bone density (BUA) and appendicular skeletal muscle mass index (appSMMI).

\begin{tabular}{|c|c|c|c|c|c|c|c|c|}
\hline $\begin{array}{l}\text { Dependent } \\
\text { Variables }\end{array}$ & Predictors & $\begin{array}{l}\text { Significant } \\
\text { Predictors }\end{array}$ & Beta & $t$ Value & Significance & $\mathbf{R}^{2}$ & Adjusted $R^{2}$ & $\mathbf{F}$ \\
\hline \multirow[t]{2}{*}{$\begin{array}{c}\text { BUA } \\
(\mathrm{dB} / \mathrm{MHz})\end{array}$} & Age (years) & Age & -0.191 & -1.939 & $0.055^{*}$ & 0.090 & 0.072 & $4.774^{* *}$ \\
\hline & $\begin{array}{c}\text { Years since menopause } \\
\text { BMI }\left(\mathrm{kg} / \mathrm{m}^{2}\right) \\
\text { BFP }(\%) \\
\text { Total } 25(\mathrm{OH}) \mathrm{D}(\mathrm{nmol} / \mathrm{L}) \\
\text { Bio } 25(\mathrm{OH}) \mathrm{D}(\mathrm{nmol} / \mathrm{L}) \\
\text { Free } 25(\mathrm{OH}) \mathrm{D}(\mathrm{pmol} / \mathrm{L})\end{array}$ & Bio $25(\mathrm{OH}) \mathrm{D}$ & 0.267 & 2.700 & $0.008^{* * *}$ & & & \\
\hline \multirow{2}{*}{$\begin{array}{c}\text { AppSMMI } \\
\left(\mathrm{kg} / \mathrm{m}^{2}\right)\end{array}$} & Age (years) & BMI & 1.326 & 11.665 & $0.000^{* * *}$ & 0.650 & 0.639 & $58.821^{* * *}$ \\
\hline & $\begin{array}{c}\text { Years since menopause } \\
\text { BMI }\left(\mathrm{kg} / \mathrm{m}^{2}\right) \\
\text { BFP }(\%) \\
\text { Total } 25(\mathrm{OH}) \mathrm{D}(\mathrm{nmol} / \mathrm{L}) \\
\text { Bio } 25(\mathrm{OH}) \mathrm{D}(\mathrm{nmol} / \mathrm{L}) \\
\text { Free } 25(\mathrm{OH}) \mathrm{D}(\mathrm{pmol} / \mathrm{L})\end{array}$ & $\begin{array}{c}\text { BFP } \\
\text { Bio } 25(\mathrm{OH}) \mathrm{D}\end{array}$ & $\begin{array}{c}-0.716 \\
0.120\end{array}$ & $\begin{array}{c}-6.112 \\
1.824\end{array}$ & $\begin{array}{c}0.000 * * * \\
0.071 *\end{array}$ & & & \\
\hline
\end{tabular}

N.B: $\mathrm{BFP}$ = body fat percent; $\mathrm{BMI}=$ body mass index; $\mathrm{BUA}$ = broadband ultrasonic attenuation; $25(\mathrm{OH}) \mathrm{D}=25$-hydroxyvitamin $\mathrm{D}$; appSMMI $=$ appendicular skeletal muscle mass index. ${ }^{*}$ Significance at $p$-value $<0.1^{* *}$ Significance at $p$-value $<0.05,{ }^{* * *}$ Significance at $p$-value $<0.01$.

Figure 2 describes the bone density (BUA dB/MHz) of participants at each quartile (from lowest to highest) of total and bioavailable 25(OH)D.

Overall results for participants showed a significant positive correlation between both forms of $25(\mathrm{OH}) \mathrm{D}$ and $\mathrm{BUA} \mathrm{dB} / \mathrm{MHz}$. However, when looking at the differences between ethnicities (Figure 2b,d), results shows that the Malaysian-Chinese reached peak bone density (BUA dB/MHz) at a lower quartile (2nd) compared to the Malaysian-Malays and Malaysian-Indians, which peaked at a higher quartile (3rd). clearpage
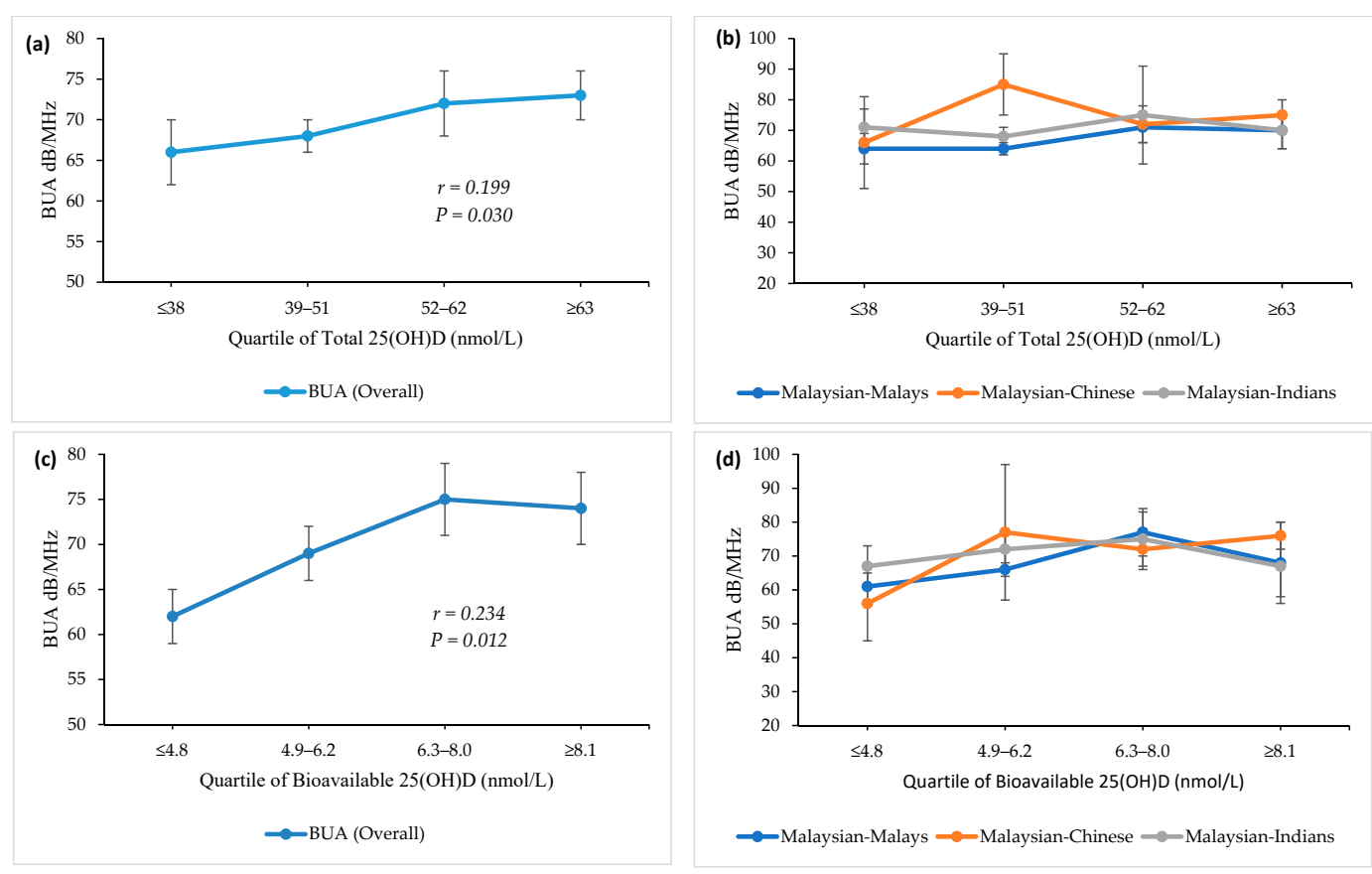

Figure 2. The BUA (broadband ultrasonic attenuation) of participants according to quartiles of Total 25-hydroxyvitamin D: (a) The results for all participants; (b) the results according to ethnicity: Malaysian-Malays, Malaysian-Chinese and Malaysian-Indians, and Bioavailable 25-hydroxyvitamin D; (c) the results for all participants; (d) the results according to ethnicity: Malaysian-Malays, Malaysian-Chinese and Malaysian-Indians. Error bar: standard ERROR of mean. 


\section{Discussion}

According to the Institute of Medicine (IOM), the threshold of $<30 \mathrm{nmol} / \mathrm{L}$ of total $25(\mathrm{OH}) \mathrm{D}$ is defined as 'deficient' [27]. This threshold was determined by markedly increased parathyroid hormone level or decreased calcium absorption in the body $[27,29,30]$. However, due to conflicting findings from experimental and epidemiological studies, the optimal threshold for the vitamin D level has not been conclusively defined [31,32]. The IOM committee suggests that the level of serum 25(OH)D that is needed for good bone health for most individuals was $50 \mathrm{nmol} / \mathrm{L}$. Further, the committee suggests that some but not all people with serum 25(OH)D levels between $30 \mathrm{nmol} / \mathrm{L}$ and $50 \mathrm{nmol} / \mathrm{L}$ are potentially at risk for vitamin D insufficiency [27]. For standardization purposes, the current study had chosen the threshold proposed by IOM (2011) to categorize the vitamin D levels [27].

In the current study, a cohort of Malaysian Malay, Chinese, and Indian postmenopausal women (141 participants), residing in Klang Valley and Semenyih, Malaysia, volunteered to participate in the study (Table 1). However, only 120 participants consented for their blood to be taken and measured for total $25(\mathrm{OH}) \mathrm{D}$, VDBP, intact parathyroid hormone (iPTH), serum calcium and serum albumin. Free and bioavailable $25(\mathrm{OH}) \mathrm{D}$ were calculated using the modified Vermuelen method for free testosterone estimation [21]. The Vermeulen method was used because this method gives separate measurements of free and bioavailable $25(\mathrm{OH}) \mathrm{D}$, rather than the Bikle method which only gives the free $25(\mathrm{OH}) \mathrm{D}[21,33]$. Nevertheless, studies have shown that the results of these two formulas are significantly correlated [33]. In this community-dwelling population of postmenopausal Malaysian women, vitamin D deficiency was rare. In fact, few participants had intact parathyroid hormone (iPTH) levels outside the normal range (Table 1, median (IQR) 5.2(3.7) pmol/L). Parathyroid Hormone (PTH) is responsible for maintaining normal levels of calcium and phosphate in the body. The hormone is regulated through the levels of serum vitamin $\mathrm{D}$ and calcium [34]. When the level of vitamin D level is high, the level of PTH is low (negative correlation), which was indeed found in the current study and presented in Table $4[35,36]$. In addition to vitamin D deficiency, an elevated PTH concentration is concerning as it is highly associated with cardio-metabolic diseases [37]. Therefore, it is important to monitor both levels of serum 25(OH)D and PTH in general health screening. The median for total 25(OH)D in the current study participants was $50 \mathrm{nmol} / \mathrm{L}$ (Table 1). On the basis of the IOM 2011 guidelines, only $7.5 \%$ of our participants would be classified as vitamin D deficient $(<30 \mathrm{nmol} / \mathrm{L}$, Table 3), while the majority of participants in this cohort were in the vitamin D replete category $(51.7 \%,>50 \mathrm{nmol} / \mathrm{L}$, Table 3$)$.

According to a 2011 report by the Malaysian Ministry of Science Technology and Innovation (MOSTI), Malaysians normally received at least $6 \mathrm{~h}$ of sunshine daily [36]. This high amount of sun exposure may be the reason for their above-average vitamin D levels. Lips also reported a low prevalence of vitamin D deficiency in Southeast Asia, particularly in Malaysia and Singapore [38]. Nevertheless, a number of previous Malaysian studies had shown contrasting findings [36,39]. For example, Shafinaz and Moy [36] reported a high prevalence of vitamin D deficiency among the Malaysian general population $(<30 \mathrm{nmol} / \mathrm{L})$, while Moy and Bulgiba [39] reported a high prevalence of vitamin D insufficiency among Malaysian women $(<50 \mathrm{nmol} / \mathrm{L})$. The reasons for the discrepancies may be due to differences in age groups, gender, and method of $25(\mathrm{OH}) \mathrm{D}$ assessment. The current study, for example, had used the chemiluminescence immunoassay (CLIA) method to assess the total $25(\mathrm{OH}) \mathrm{D}$, which had been proven to be highly sensitive and consistently used for clinical diagnosis [40]. On the other hand, some immunoassays, such as the ones that come in ready-to-use kit versions, may underestimate $25(\mathrm{OH}) \mathrm{D}$ metabolites due to the differences in the affinity between the antibodies or D-binding protein employed. Nevertheless, the ethnic disparities in 25(OH)D levels in the current study were consistent with findings of previous Malaysian studies [36,41,42]. The current study found that women of Indian and Malay ethnicity had significantly lower vitamin D level $(<50 \mathrm{nmol} / \mathrm{L})$ compared to the Chinese ( $>50 \mathrm{nmol} / \mathrm{L}, p$-value $<0.05$, Figure 1). Comparatively, Rahman et al. [42] also 
reported that the level of total $25(\mathrm{OH}) \mathrm{D}$ was significantly lower in the postmenopausal Malaysian-Malay women (44.4 [10.6] nmol/L) compared to the Malaysian-Chinese women (68.8 [15.7] nmol/L).

Studies have consistently found race/ethnicity to be one of the strongest indicators of vitamin D status [36,41,42]. Theoretically, one of the reasons was due to melanin content in the skin. Malaysian-Indians and Malaysian-Malays normally have higher melanin content in the skin (Fitzpatrick skin type VI and types V and VI, respectively) compared to the Malaysian-Chinese (types III and IV) [43]. Higher melanin content inhibits vitamin D synthesis [42]. Studies have found that longer sun exposure is needed by people with darker skin color or higher melanin content in order to produce the same amount of vitamin D levels compared to those with lighter skin color [44]. Although Malaysia is a country with plenty of sunlight all year round, a number of findings showed that the women, particularly of Malay ethnicity, tend to have low vitamin D levels [36,38,39,42]. The Malays constituted about $60 \%$ of the country's population and they are Muslims by religion. Previous studies have shown that Malaysian-Malays tend to stay indoors and avoid the extreme heat of mid-day sun [42]. Although humans only need to be exposed to sunlight for about 15 min during mid-day to obtain adequate vitamin D levels, the clothing habits of Malaysian-Malay women (i.e, headscarf, long sleeves, long skirts) which only exposed the UV radiation to face and hands, as well as darker pigmentation, reduced the synthesis of vitamin D in the skin [38,42]. However, self-identification of ethnicity by participants in the current study posed a limitation, reducing the ability of the current study to make valid conclusion. Participants identified their ethnicity through a simple question in the questionnaire. Further, the skin pigmentation was not directly measured using appropriate spectrometric devices, reducing the ability of the current study to make causal inferences. However, although the ethnicity of the current study's participants was self-identified, the results of the current study (Figure 1) echoed prior Malaysian studies' in relation to ethnic disparities in vitamin D levels $[36,41,42]$. In the case of free and bioavailable $25(\mathrm{OH}) \mathrm{D}$, the levels of these two forms of $25(\mathrm{OH}) \mathrm{D}$ reflects the level of total $25(\mathrm{OH}) \mathrm{D}$ (Figure 1 and Table 4). Collectively, the median for bioavailable $25(\mathrm{OH}) \mathrm{D}$ for this study cohort was $2.5 \mathrm{ng} / \mathrm{mL}$ (Table 1), comparable to previous findings in healthy women in Seoul, Korea (2.6 ng/mL) [10] and Shanghai, China (2.9 ng/mL) [45].

Current and other studies have shown that obesity was negatively associated with serum total 25(OH)D level [45]. However, it was unclear which indicator of obesity, i.e., BMI, waist circumference, (WC) or percentage of body fat (BFP) should be taken into consideration while assessing vitamin $\mathrm{D}$ status in the general population. The current study found no differences in BMI and WC between the vitamin D deficient, insufficient, and the replete group (Table 3). Interestingly, findings from the current study suggest that there may be a certain degree of body fat percentage (BFP) that may trigger the negative association with vitamin D. For example, the current study found that the BFP of people in the Replete group $(38.8 \%)$ was significantly lower ( $p$-value $<0.05)$ than the Deficient and Insufficient groups (43.6\% and $43.1 \%$, respectively, Table 3$)$, although it was still above the threshold for osteopenic-related obesity level (BFP $\geq 32 \%$ ) [24].

When compared with vitamin D deficient group, people in the vitamin $\mathrm{D}$ replete group had significantly lower iPTH level, and significantly higher bone density (BUA) and faster walking speed (Table $3, p$-value $<0.05$ ). The vitamin D replete group also had significantly higher serum calcium and bioavailable $25(\mathrm{OH}) \mathrm{D}$ concentration than vitamin D deficient group (Table 3). Between the three groups of vitamin D deficient, insufficient, and replete, there were no significant differences in the HGS, muscle mass, lower extremity strength (sit-to-stand test), balance, and VDBP (Table 3). Nevertheless, vitamin $\mathrm{D}$ has been described to have a U-shaped relationship with the physical function where plasma 25(OH)D levels greater than $120 \mathrm{nmol} / \mathrm{L}$ was found to be associated with a poorer physical performance [46]. Therefore, non-significant differences between the groups may not indicate a lack of correlations. Perhaps a dose-dependent study could confirm the U-shaped relationship. 


\subsection{Vitamin D and Bone Density}

Studies have consistently found a significant and positive relationship between vitamin D and bone health [47]. Vitamin D increases the absorption of calcium in the gut, regulates the mineralization of bone tissue and may play an important role in muscle function [48]. Recent evidence suggests that the unbound or the bioavailable fraction of $25(\mathrm{OH}) \mathrm{D}$ may be a better indicator of vitamin $\mathrm{D}$ status compared to total $25(\mathrm{OH}) \mathrm{D}$ as it has been shown to correlate better with bone density [45]. The free hormone hypothesis posits that the free and/or bioavailable fractions of $25(\mathrm{OH}) \mathrm{D}$ may correlate more strongly with its biological action than the total $25(\mathrm{OH}) \mathrm{D}$ due to their higher biological 'availability' [49]. Currently, there are limited assessments of bioavailable 25(OH)D in the Asian population. So far, there was only one other study which had examined the free hormone hypothesis related to $25(\mathrm{OH}) \mathrm{D}$ in a cohort of Malaysian women [33]. However, the study was conducted on women with rheumatoid arthritis (mean age 53.7 years) and the results may not be applicable to the general, community-dwelling population.

In the current cross-sectional study, Pearson's correlation coefficient analysis revealed that both the bioavailable $25(\mathrm{OH}) \mathrm{D}$ and total $25(\mathrm{OH}) \mathrm{D}$ levels were positively correlated with the BUA (Table 4 and Figure 2, $p$-value $<0.05$ ). Interestingly, when divided by ethnicity, the Malaysian-Chinese achieved peak (highest) BUA at a lower concentration of total 25(OH)D (Figure 2) and bioavailable 25(OH)D (Figure 2) compared to MalaysianMalays and Malaysian-Indians (second quartile vs. the third quartile). The reason for this may be due to existing calcium concentrations. A prior study has reported that calciumsufficient people need less vitamin D [47]. Heaney [47] found that African-Americans had better renal conservation of calcium (more efficient calcium economy) compared to Caucasians, which explains why, despite their low vitamin D level, African-Americans have a lower risk of osteoporotic fractures than do Caucasians [50]. Indeed, in the current study, the Malaysian-Chinese had significantly higher calcium concentration compared to Malaysian-Malays and Malaysian-Indians (Figure 1), thus do not need as much vitamin D to aid calcium absorption in the gut for bone remodeling (i.e., higher BUA at a lower levels of vitamin D).

In the Stepwise regression analyses, the current study identified age and bioavailable $25(\mathrm{OH}) \mathrm{D}$, (but not total 25(OH)D) as significant predictors for BUA and these two variables explained $7.2 \%$ of the variance (Table 5 ). Age was found to be negatively correlated $(\beta=-0.191)$, while bioavailable $25(\mathrm{OH}) \mathrm{D}(\beta=0.267)$ was positively correlated with bone density. Interestingly, even without any adjustment of variables, the Pearson's correlation coefficient of bioavailable $25(\mathrm{OH}) \mathrm{D}$ to the $\mathrm{BUA}$ was still marginally stronger compared to total 25(OH)D $[r=0.234, p$-value $=0.012$ and $r=0.199, p$-value $=0.030$, respectively, Figure $2 \mathrm{a}, \mathrm{c}]$. These findings support the findings by Li et al. [45] which found that bioavailable $25(\mathrm{OH}) \mathrm{D}$ levels (but not total 25(OH)D levels) were an independent determinant of the bone mineral density (BMD) values after adjusted for age, body mass index, and bone turnover biomarkers (OST and $\beta-\mathrm{CTX}$ ) in postmenopausal women. We also found that there was a slightly stronger correlation between the iPTH concentrations and bioavailable 25(OH)D than with the total 25(OH)D level (Table 4). However, in the current study, the small effect size (Pearson's r) and the small percent of variance are insufficient to conclude the superior status of bioavailable 25(OH)D. More research is needed with a larger sample size to validate this finding.

To date, several epidemiological studies have determined the correlation between levels of different forms of $25(\mathrm{OH}) \mathrm{D}$ and bone density in healthy populations, but inconclusive results were found. A study by Johnsen et al. [49] on the correlations between different forms of $25(\mathrm{OH}) \mathrm{D}$ and $\mathrm{BMD}$ found that bioavailable or free $25(\mathrm{OH}) \mathrm{D}$ was the superior indicator for vitamin D assessment compared to total 25(OH)D [49]. Conversely, a study with 304 adults aged between 21 and 81 years found no significant association between any form of 25(OH)D and BMD [51]. In the current study, our findings supported the former (Table 5). In addition to BUA, we also found a significant and positive correlation of bioavailable 25(OH)D with other QUS indices (results reported elsewhere). When age, 
years since menopause, obesity index (BMI and BFP), and 25(OH)D index were tested as predictors, the strongest correlations to BUA were found for age and bioavailable $25(\mathrm{OH}) \mathrm{D}$, suggesting the superior role of the metabolite compared to total $25(\mathrm{OH}) \mathrm{D}$ (Table 5$)$. This is somewhat supported the findings by Lim et al. [52], who found that increased age was positively associated with osteoporosis among healthy Malaysian women ( $\geq 45$ years). In addition, Chan et al. [53] also found that the predictors of suboptimal bone health and osteoporosis among 786 Malaysians aged $>40$ years were increased age and higher fat mass. Interestingly, we found no evidence for the obesity paradox which hypothesized that obesity is correlated with higher bone density (Table 4). No significant correlations were found between indicators of obesity (BMI and BFP) and BUA (Tables 4 and 5), suggesting that women with higher adiposity may not have higher bone density. This is consistent with previous studies reporting no correlations between obesity and high BMD [53]. However, it is fair to note that for obese populations, there is a U-shape relationship between $\mathrm{BMI}$ and BMD and that the protective effects of weight on bone are reduced along with the increment of BMI [54]. Palermo et al. [54] found that the protective effects of weight on bone only went up to a certain level, and decreased along with the increment of BMI. So far, many studies exploring the relationships between obesity and bone density in human subjects had been observational in nature. Further studies with identifiable confounding factors are needed in order to determine the impact of obesity on bone density.

\subsection{Vitamin D and Muscle Mass}

In muscle, the active form of vitamin D was theorized to stimulate muscle cell proliferation and growth by activating vitamin D receptors (VDR) that mediate both gene transcription and rapid non-transcriptional signal transduction. This, in turn, will regulate protein synthesis and calcium handling involved in muscle cell development [55]. Vitamin D has been found to play a significant role in muscle function in a number of studies [56,57]. For example, a Korean study involving adults aged 40 years and older showed that men with vitamin D deficiency (defined as serum $25(\mathrm{OH}) \mathrm{D}<20 \mathrm{ng} / \mathrm{mL}$ ) had lower appendicular skeletal muscle mass (appSMMI) than those with a higher level of vitamin D. No correlation, however, was found in women [57]. Other studies have found similar findings. For example, Visser, Deeg \& Lips [58] found that after adjustment for physical activity level, the season of data collection, serum creatinine concentration, chronic disease, smoking, and BMI, older adults with low baseline $25(\mathrm{OH}) \mathrm{D}$ levels $(<25 \mathrm{nmol} / \mathrm{L})$ were 2.14 times (0.73-6.33, based on appendicular skeletal muscle mass) more likely to experience sarcopenia compared to those with high $25(\mathrm{OH}) \mathrm{D}$ levels $(>50 \mathrm{nmol} / \mathrm{L})$. Interestingly, in the current study, stepwise regression analysis revealed a significant and positive correlation between bioavailable 25(OH)D (but not total 25(OH)D) and appSMMI (Table 5, $p$-value <0.10). Similar to bone density (BUA), bioavailable 25(OH)D was found to be superior to total $25(\mathrm{OH}) \mathrm{D}$ in its correlation to muscle mass (appSMMI, Table 5). However, more than bioavailable $25(\mathrm{OH}) \mathrm{D}$, a big proportion of the appSMMI variance was explained by the obesity indices, which includes BMI and BFP ( $p$-value $<0.05$, Table 5). Indeed, the current study found a significant and positive correlation between obesity (BFP) and muscle mass (appSMMI, Table 4). It is entirely possible that vitamin D may play a role in the parallel increase of muscle mass along with fat. Whilst vitamin D is primarily stored in adipose tissue, there is evidence of vitamin D uptake in skeletal muscle [59]. Vitamin $\mathrm{D}$ uptake in skeletal muscle may help the muscle grow along with body fat as a part of body's adaptation to compensate for the increase in body mass (i.e., Davis's law, which is a corollary to Wolff's Law, describes how soft tissue increase according to the manner in which they are mechanically stressed) [60].

In addition to a deficit in muscle mass, hypovitaminosis $\mathrm{D}$ has also been found to be significantly associated with a decrease in lower limb strength in older men and women [9]. A cross-sectional study conducted by Ahern et al. [61] reported slower walking speed in 252 severely obese and vitamin D deficient adults [61]. In the current study, we found that different forms of $25(\mathrm{OH}) \mathrm{D}$ are correlated with different components of functional 
performance (Table 4). For example, total $25(\mathrm{OH}) \mathrm{D}$ was found to be significantly and positively correlated with walking speed (GS), whereas bioavailable $25(\mathrm{OH}) \mathrm{D}$ was found to be correlated with lower extremity strength (STS, Table $4, p$-value $<0.05)$. These observed associations suggest that regardless of fractions of vitamin $\mathrm{D}$, older women with low vitamin D level may be at a higher risk for future falls and fall-related injury due to weaker lower body strength. Other studies have also reported significant associations between low vitamin D status and subsequent falls risk, a decline in physical performance and development of sarcopenia in the elderly $[58,62,63]$.

\section{Materials and Methods}

\subsection{Selection and Recruitment of Participants}

One hundred and forty-one $(n=141)$ postmenopausal women comprised of Malay, Chinese and Indian ethnicity (aged 45-88 years) residing in Klang Valley and Semenyih, Malaysia volunteered to participate in the study. Of which, one hundred and twenty $(n=120)$ women consented to their blood being collected and analyzed for intact parathyroid hormone (iPTH), albumin, calcium, vitamin D binding protein (VDBP), and total 25(OH)D. One sample for iPTH was excluded from analysis due to being an outlier and 4 samples for VDBP were excluded due to the high percentage of coefficient variations $(>15 \% \mathrm{CV})$. Free and bioavailable $25(\mathrm{OH}) \mathrm{D}$ were calculated using a modified Vermuelen method for free testosterone estimation [21,64]. Postmenopausal was defined as having no menstrual period, bleeding, or spotting during the 12 consecutive months prior to enrollment, and was assessed using a questionnaire. Before enrollment, details about the study covering the objectives, procedures, benefits, risks, and possible discomforts from the study were briefed to interested participants. Apparently healthy and interested participants were screened for eligibility with the following inclusion criteria: (i) A woman, (ii) Citizen of Malaysia (of Malay, Indian or Chinese ethnicity), (iii) Postmenopausal (no menstrual period, bleeding, or spotting 12 consecutive months prior to enrolment). Exclusion criteria included: (i) Inability to stand for height, weight and gait speed assessments, (ii) Presence of artificial limbs and/or metal implants, (iii) Severe cardiac, pulmonary, or musculoskeletal disorders, (iv) Severe cognitive impairment or any disability that makes communication impossible, and (v) Presence of terminal illness. Eligible participants were explained further on the purpose and procedure of the study and were asked to give written consent. This study was conducted according to the guidelines laid down in the Declaration of Helsinki and all procedures involving research study participants were approved by the Science and Engineering Research Ethics Committee of the University of Nottingham Malaysia [SEREC- NZA051016].

\subsection{Demographic Status}

Demographic information was collected using a structured and validated questionnaire with items including age, sex, level of education, history of diseases/co-morbidities, and self-rated level of physical activity. Questions on menstrual status were taken from the Menopause Health Questionnaire, The North American Menopause Society (e.g., 'how would you describe your current menstrual status?' with options to choose pre-menopause, peri-menopause and post-menopause, each provided with definitions).

\subsection{Anthropometric and Obesity Indices Measurements}

\subsubsection{Height}

Height was measured to the nearest $0.1 \mathrm{~cm}$ using a portable stadiometer (SECA 217, Vogel \& Halke GmbH \& Co., Hamburg, Germany). Participants were asked to stand with their shoulders, buttocks and heels resting against the stadiometer, toe tips forming a $45^{\circ}$ angle, heels touching each other, head held straight and neck in a natural position. 


\subsubsection{Body Fat Percentage and Body Mass Index}

Body fat percentage and body mass index was assessed using a segmental bio-electrical impedance analyzer (InBody 230 Body Composition Analyzer, Biospace Co. Ltd., Seoul, Korea). While on this machine, the weight of the participant was automatically generated.

\subsubsection{Waist Circumference}

A measuring tape (SECA 203, GmbH \& Co. Kg., Hamburg, Germany) was used to measure waist circumference. Waist circumference $(\mathrm{cm})$ was measured at the mid-point between the last rib and the anterior superior iliac spine with subjects standing upright [23].

\subsection{Bone Density Index Measurement Quantitative Ultrasound (QUS) Bone Assessments}

Bone density was assessed using calcaneal ultrasound bone densitometer (SAHARA ${ }^{\circledR}$ Clinical Bone Sonometer, Hologic Inc, Waltham, MA, USA). Prior studies using quantitative ultrasound (QUS) found that high-frequency sound waves were attenuated easier by bone compared to low-frequency sound waves. Ultrasonic sound waves in the frequency range of 0.2 to $0.6 \mathrm{MHz}$ were found to be linearly correlated with the level of attenuation. The slope of the linear regression of these two parameters (attenuation versus sound waves in the frequency range) was defined as broadband ultrasound attenuation (BUA), and is measured in $\mathrm{dB} / \mathrm{MHz}$. On the SAHARA ${ }^{\circledR}$ system, the BUA and Speed of Sound (SOS) are measured simultaneously. In order to determine the sound attenuation of the heel alone, without any bias arising from the transducers and/or transducer pads, a comparison measurement was made through a reference medium (SAHARA ${ }^{\circledR}$ QC Phantom supplied with the SAHARA ${ }^{\circledR}$ unit when the unit was calibrated at the factory). While SAHARA ${ }^{\circledR}$ densitometers do not directly measure bone mineral density (BMD), the BUA and SOS results are correlated $(r=0.82-0.85)$ with heel BMD results obtained by the standard Dual Energy X-ray Absorptiometry (DXA) technique [65].

\subsection{Muscle Mass Indices Measurements}

Appendicular Skeletal Muscle Mass Index (appSMMI)

Muscle mass indices [skeletal muscle mass (SMM), fat-free mass (FFM) and appendicular skeletal muscle mass (appSMM)] were assessed using segmental bio-electrical impedance analyzer (BIA, InBody 230 Body Composition Analyzer, Biospace Co. Ltd., Seoul, Korea). Appendicular skeletal muscle mass was calculated by adding the weight of the muscle masses of the four limbs. Appendicular Skeletal Muscle Mass Index (appSMMI) was defined as the sum of the muscle masses of the four limbs, adjusted for height in squared meters $(\mathrm{kg}) /$ height $^{2}$. AppSMMI was first suggested by Baumgartner et al. [66] in the New Mexico Elder Health Survey. This index provided significant associations with physical disability or frailty.

\subsection{Muscle Strength}

Handgrip strength was assessed as a proxy for muscle strength and was measured in each hand using a hand dynamometer (JAMAR Hydraulic Hand Dynamometer ${ }^{\circledR}$ Model PC-5030 J1, Fred Sammons, Inc., Burr Ridge, IL, USA). Handgrip strength was measured twice for each hand, and the higher of the two values was recorded. Then, the higher value of the two hands was used in the analysis. Standardized positioning recommended by The American Society of Hand Therapists (ASHT) was used: subject seated, shoulders adducted and neutrally rotated, elbow flexed at $90^{\circ}$, forearm in neutral and wrist between 0 and $30^{\circ}$ of dorsiflexion [67].

\subsection{Functional Performance}

4.7.1. Short Physical Performance Battery (SPPB) Test

Functional performance was assessed using modified components of the short physical performance battery (SPPB) test. Based on the recommendation by Ilich, Kelly and 
Inglis [24], the following tests were conducted under the SPPB: one-leg stance (to test balance), gait speed (to test endurance), and sit-to-stand chair test (to assess lower extremity strength). The SPPB has an internal consistency of 0.76 and has predictive validity for the risk of mortality, nursing home admission, and disability [68].

\subsubsection{One-Leg Stance}

For the one-leg stance, measurements for both the right and left legs were assessed. The test requires participants to stand on one leg while lifting the other limb, for a maximum of $30 \mathrm{~s}$. The test stops when the participant touches any surface or lowers the other limb to the ground or, ultimately, at the end of $30 \mathrm{~s}$ [24].

\subsubsection{Gait Speed}

Gait speed was measured by timing a 6-m normal walk. The 6-m course was marked by two cones or pieces of tape measured using a roll-up, self-retracting construction measuring tape. The test requires the participant to walk at a normal pace starting at one end of the course and all the way past the other. The timing starts when the tester/instructor command "begin" and stops when one of the participant's feet is all the way across the 6-m marker. If the participants normally use a cane or any other walking devices, they were allowed to use them while performing the test.

\subsubsection{Sit-to-Stand Chair Test}

At the beginning of this test, the participant was seated in an armless chair, with arms crossed over the chest, back straight, and feet flat on the floor. At the maximum of $30 \mathrm{~s}$, the test requires the participant to rise from the chair and sit down again as many times as possible. The number of consecutive chair sit-to-stand tests completed was recorded, with the last time the participant sat down in the chair being the final count.

\subsection{Laboratory Measurements}

Blood samples were collected by a trained phlebotomist, processed and stored at $-80{ }^{\circ} \mathrm{C}$ until measurement. Blood serum was collected using yellow-topped plasma tubes (SST) and plasma was collected using lavender-topped plasma tubes (EDTA as additive). All blood samples were centrifuged at $1200 \times g$ for $15 \mathrm{~min}$, aliquoted, and stored at $-80{ }^{\circ} \mathrm{C}$ until measurement. Serum VDBP was measured using ELISA technique [Quantikine ELISA kit (R\&D Systems, Minneapolis, MN, USA, Product code: GZ-DVDBP0B)] that employs quantitative sandwich enzyme immunoassay using a monoclonal antibody. The intra-assay CV was $5.4 \%$. The \% recovery was $100.13 \%$ (MyAssays.com). Serum total 25(OH)D concentrations were measured using chemiluminescent microparticle immunoassay CMIA on Siemens ${ }^{\circledR}$ platforms (Siemens AG, Munich, Germany). Serum albumin levels were measured by using BCG Dye bonding on ADVIA ${ }^{\circledR} 2400$ Clinical Chemistry System (Siemens AG, Munich, Germany), plasma intact parathyroid hormone levels was measured using 2-site sandwich microparticle immunoassay on Siemens ${ }^{\circledR}$ ADVIA ${ }^{\circledR}$ Centaur XP immunoassay system (Siemens AG, Munich, Germany), and serum calcium level was measured using Arsenazo III Method on ADVIA ${ }^{\circledR} 2400$ Clinical Chemistry System (Siemens AG, Munich, Germany). Free and bioavailable 25(OH)D were calculated from total 25(OH)D, VDBP, and serum albumin concentrations using Vermuelen method for free testosterone estimation $[16,21,64,69,70]$ (Supplementary Material 1):

Bioavailable 25(OH)D = free 25(OH)D + albumin bound 25(OH)D

$$
\text { Free } 25(\mathrm{OH}) \mathrm{D}=\left[-\mathrm{b}+\sqrt{\mathrm{b}^{2}-4 \mathrm{ac}}\right] \div 2 \mathrm{a}
$$

Bioavailable 25(OH)D $=[$ Free 25(OH)D $]+[\mathrm{DAlb}]=\left(\mathrm{K}_{\mathrm{alb}} \times[\mathrm{Alb}]+1\right) \times$ Free $25(\mathrm{OH}) \mathrm{D}$

$$
\mathrm{a}=\mathrm{K}_{\mathrm{VDBP}} \times \mathrm{K}_{\mathrm{alb}} \times[\mathrm{Alb}]+\mathrm{K}_{\mathrm{VDBP}}
$$




$$
\begin{aligned}
& \mathrm{b}=\left(\mathrm{K}_{\mathrm{VDBP}} \times[\mathrm{VDBP}]\right)-\left(\mathrm{K}_{\mathrm{VDBP}} \times[\text { Total } 25(\mathrm{OH}) \mathrm{D}]\right)+\left(\mathrm{K}_{\mathrm{alb}} \times[\mathrm{Alb}]\right)+1 \\
& \mathrm{c}=-[\text { Total } 25(\mathrm{OH}) \mathrm{D}] \\
& \mathrm{K}_{\mathrm{alb}}=\text { affinity constant between } 25(\mathrm{OH}) \mathrm{D} \text { and albumin }=6 \times 10^{5} \mathrm{M}^{-1} \\
& \mathrm{~K}_{\mathrm{VDBP}}=\text { affinity constant between } 25(\mathrm{OH}) \mathrm{D} \text { and } \mathrm{VDBP}=7 \times 10^{8} \mathrm{M}^{-1}
\end{aligned}
$$

$[\mathrm{Alb}]=$ concentration of albumin

[Total 25(OH)D] = concentration of total 25(OH)D

$$
\text { [VDBP] }=\text { concentration of VDBP }
$$

$$
\text { [DAlb] = Albumin-bound 25(OH)D = Bioavailable 25(OH)D-Free 25(OH)D }
$$

Calculations of all forms of $25(\mathrm{OH}) \mathrm{D}$ were done in moles per liter $(\mathrm{mol} / \mathrm{L})$ using the Vermeulen method as it provides separately for free and bioavailable $25(\mathrm{OH}) \mathrm{D}$. Subsequently, bioavailable $25(\mathrm{OH}) \mathrm{D}$ was converted to nanomoles per litre $(\mathrm{nmol} / \mathrm{L})$ while free $25(\mathrm{OH}) \mathrm{D}$ was expressed as nmol/L and picomoles per litre (pmol/L) (please refer to the Supplementary Material 1 for the conversion table).

\subsection{Statistical Analysis}

Statistical analyses were performed using IBM SPSS (Statistical Package for Social Sciences) version 24 for Windows (SPSS, Inc., Chicago, IL, USA). Variables were checked for normality (Shapiro-Wilk test) and presented as mean \pm standard deviation or median (interquartile range). Where possible, analyses were stratified by ethnicity. Frequency and percentages were reported for categorical variables. Outliers were detected using 'outlier labeling rule', which is based on multiplying the Interquartile Range (IQR) by a factor of 2.2 to get the higher or lower range of the data [71]. A comparison of the distributions of various parameters between groups was performed using a standard ANOVA (analysis of variance) or ANOVA's Welch Test (dependent on the smallest number of sample size). When significant differences were found with ANOVA, the post-hoc Tukey's HSD (honestly significant difference) or Games-Howell test was applied to correct for use of multiple comparisons. Pearson's correlation analysis was used to assess the correlation of each of the characteristics with the target outcomes. Stepwise regression analysis was used to determined significant predictors for bone density and muscle mass. Two-tailed $p$-value $\leq 0.05$ was recognized as statistically significant, unless stated otherwise.

\section{Conclusions}

Although in the current study, bioavailable $25(\mathrm{OH}) \mathrm{D}$ was found to be superior to total 25(OH)D in its correlation to bone density (BUA) and muscle mass (appSMMI), it is still premature to draw any conclusion on the relationship due to the small effect size $\left(R^{2}\right)$ and Pearson's $r$ value. More research is needed with a larger sample size in order to validate these findings. Nevertheless, the significant correlation found between bioa-vailable $25(\mathrm{OH}) \mathrm{D}$ levels and bone density shows that it may be helpful in clinical prac-tices when assessing bone health in postmenopausal women. Experts generally agree that a minimum level of $50 \mathrm{nmol} / \mathrm{L}$ of $25(\mathrm{OH}) \mathrm{D}$ must be reached in the general elderly population and that $75 \mathrm{nmol} / \mathrm{L}$ should be the target in fragile people who are at ele-vated risk for falls and fractures [72,73]. Vitamin D supplementation is generally safe and inexpensive. Therefore, it is highly recommended in patients at risk for falls, such as the elderly, institutionalized patients, frail patients, and patients with chronic diseases. These individuals tend to have low levels of vitamin D and muscle disorders. Therefore, supplementation is justified regardless of any assumed effect on the prevention of falls. Further, the current study shows evidence on the negative implication of obesity on total vitamin D levels, and that the levels of bioavailable $25(\mathrm{OH}) \mathrm{D}$ is dependent on the levels of VDBP. This study is worth further exploration. The findings could revolutionize the testing for vitamin D status in the general population, particularly in vulnerable groups such as the obese. 


\subsection{Limitations}

This study has some limitations. First, the cross-sectional design of the study prevents us from making any causal inferences. Second, skin pigmentation was not directly measured, limiting our ability to validate the differences in 25(OH)D levels between ethnicities. For future studies, it is better to measure the variability of skin pigmentation using a measurement device such as spectrophotometer (Konica Minolta CM700d) or telespectroradiometer (PhotoResearch PR650). Third, ethnic classification was based on self-identification (asked on the questionnaire as 'What is best described as your ethnicity?'), and therefore is considered as non-scientifically accurate ethnic classification. Nevertheless, self-identification of ethnicity has always been used even in Malaysian national census and Malaysians are generally used to providing information on their ethnicity [74]. Further, genotype-specific affinity constants were not used in the calculation of free and bioavailable 25(OH)D due to unavailable data on VDBP polymorphisms in the Malaysian population. This may be a confounding factor. Nevertheless, Li et al. [45] suggest that the VDBP variants account for only a small proportion of the bioavailable $25(\mathrm{OH}) \mathrm{D}$ variation as they found no associations between the VDBP level and the presence of VDBP variants rs4588 and rs7041 with bone density. However, there is merit in studying the Group-specific Component (GC) phenotype due to evidence showing a high degree of polymorphism in VDBP [75]. Genetically, VDBP is highly polymorphic with three frequent alleles (DBP/GC 1f, 1s, and 2) and over 120 variants [75]. Currently, the health consequences of this polymorphism are not yet understood. Therefore, there is a need to standardize the assays for serum VDBP so that the role of VDBP in the manifestation of diseases can be determined. Finally, the current study had used ultrasound and bio-electrical impedance analyzer to measure bone density and muscle mass. For future studies, it is better to use the gold standard spectral imaging such as Dual-energy X-ray absorptiometry (DEXA) as the measurement tool for bone density and body composition in order to increase the validity of the study.

\subsection{Strengths}

Notwithstanding the above limitations, the current study had several strengths. One of the strengths of this study lies in the representativeness of the study sample which includes the 3 major ethnicities in Malaysia (e.g., Malaysian-Malays, Malaysian-Chinese and Malaysian-Indians), which described the differences of vitamin D levels of multi-races with similar environments, crediting the external validity of the results. Further, the older participants were non-institutionalized, allowing direct extrapolation to older persons of the population at large. In addition, we determined the better biomarker between total and bioavailable $25(\mathrm{OH}) \mathrm{D}$ levels in relation to bone and muscle indices, which could lead to the elucidation of the underlying mechanisms for the effects of $25(\mathrm{OH}) \mathrm{D}$ on osteoporosis and sarcopenia.

Supplementary Materials: The following are available online at https:/ /www.mdpi.com/2218-198 9/11/1/23/s1, Supplementary Material 1: Calculations of Free and Bioavailable 25-hydroxyvitamin D based on Vermeulen's equations, Table S1: Conversion table for free and bioavailable 25(OH)D calculations.

Author Contributions: N.Z.A. conceived, designed the study, analyzed and interpreted the data, and drafted the manuscript. S.R.M. was involved in the supervision of the research process and critical revision and review of the manuscript. All the authors read and approved the final manuscript. All authors have read and agreed to the published version of the manuscript.

Funding: This research received no specific grant from any funding agency in the public, commercial, or not-for-profit sectors.

Institutional Review Board Statement: This study was conducted according to the guidelines laid down in the Declaration of Helsinki and all procedures involving research study participants were approved by the Science and Engineering Research Ethics Committee of the University of Nottingham Malaysia [SEREC- NZA051016].

Informed Consent Statement: Informed consent was obtained from all subjects involved in the study. 
Data Availability Statement: The data presented in this study are openly available in FigShare at https:/ / doi.org/10.6084/m9.figshare.13317857.v1.

Acknowledgments: We wish to thank the students at the School of Biosciences, University of Nottingham Malaysia for their collaborative effort during data collection, Malaysian Menopause Society, Grace Assembly of God Kajang, Praise Evangelical Assembly and everyone who assisted us with the data collection and analysis. We also would like to thank the participants that took part in the study and enabled this research to be possible.

Conflicts of Interest: The authors declare no conflict of interest.

\section{References}

1. Laurent, M.R.; Dubois, V.; Claessens, F.; Verschueren, S.M.; Vanderschueren, D.; Gielen, E.; Jardí, F. Muscle-bone interactions: From experimental models to the clinic? A critical update. Mol. Cell Endocrinol. 2016, 432, 14-36. [CrossRef]

2. Bruyère, O.; Cavalier, E.; Reginster, J.Y. Vitamin D and osteosarcopenia: An update from epidemiological studies. Curr. Opin. Clin. Nutr. Metab. Care. 2017, 20, 498-503. [CrossRef]

3. Christakos, S.; Dhawan, P.; Verstuyf, A.; Verlinden, L.; Carmeliet, G. Vitamin D: Metabolism, Molecular Mechanism of Action, and Pleiotropic Effects. Physiol. Rev. 2016, 96, 365-408. [CrossRef]

4. Sadat-Ali, M.; Al Elq, A.H.; Al-Turki, H.A.; Al-Mulhim, F.A.; Al-Ali, A.K. Influence of vitamin D levels on bone mineral density and osteoporosis. Ann. Saudi Med. 2011, 31, 602-608. [CrossRef]

5. Cheng, S.; Massaro, J.M.; Fox, C.S.; Larson, M.G.; Keyes, M.J.; McCabe, E.L.; Robins, S.J.; O’Donnell, C.J.; Hoffmann, U.; Jacques, P.F.; et al. Adiposity, cardiometabolic risk, and vitamin D status: The Framingham Heart Study. Diabetes 2010, 59, $242-248$. [CrossRef]

6. Earthman, C.P.; Beckman, L.M.; Masodkar, K.; Sibley, S.D. The link between obesity and low circulating 25-hydroxyvitamin D concentrations: Considerations and implications. Int. J. Obes. 2012, 36, 387-396. [CrossRef]

7. Grethen, E.; McClintock, R.; Gupta, C.E.; Jones, R.; Cacucci, B.M.; Diaz, D.; Fulford, A.D.; Perkins, S.M.; Considine, R.V.; Peacock, M. Vitamin D and hyperparathyroidism in obesity. J. Clin. Endocrinol. Metab. 2011, 96, 1320-1326. [CrossRef]

8. Roth, S.M.; Zmuda, J.M.; Cauley, J.A.; Shea, P.R.; Ferrell, R.E. Vitamin D receptor genotype is associated with fat-free mass and sarcopenia in elderly men. J. Gerontol. A Biol. Sci. Med. Sci. 2004, 59, 10-15. [CrossRef]

9. Scott, D.; Blizzard, L.; Fell, J.; Ding, C.; Winzenberg, T.; Jones, G. A prospective study of the associations between 25-hydroxyvitamin D, sarcopenia progression and physical activity in older adults. Clin. Endocrinol. 2010, 73, 581-587. [CrossRef]

10. Kim, J.; Lee, Y.; Kye, S.; Chung, Y.S.; Lee, O. Association of serum vitamin D with osteosarcopenic obesity: Korea National Health and Nutrition Examination Survey 2008-2010. J. Cachexia Sarcopenia Muscle. 2017, 8, 259-266. [CrossRef]

11. Rosendahl-Riise, H.; Spielau, U.; Ranhoff, A.H.; Gudbrandsen, O.A.; Dierkes, J. Vitamin D supplementation and its influence on muscle strength and mobility in community-dwelling older persons: A systematic review and meta-analysis. J. Hum. Nutr. Diet. 2017, 30, 3-15. [CrossRef]

12. Kotlarczyk, M.P.; Perera, S.; Ferchak, M.A.; Nace, D.A.; Resnick, N.M.; Greenspan, S.L. Vitamin D deficiency is associated with functional decline and falls in frail elderly women despite supplementation. Osteoporos. Int. 2017, 28, 1347-1353. [CrossRef]

13. Al-Eisa, E.S.; Alghadir, A.H.; Gabr, S.A. Correlation between vitamin D levels and muscle fatigue risk factors based on physical activity in healthy older adults. Clin. Interv. Aging 2016, 11, 513-522.

14. Hirani, V.; Cumming, R.G.; Naganathan, V.; Blyth, F.; Le Couteur, D.G.; Hsu, B.; Handelsman, D.J.; Waite, L.M.; Seibel, M.J. Longitudinal Associations Between Vitamin D Metabolites and Sarcopenia in Older Australian men: The Concord Health and Aging in Men Project. J. Gerontol. A Biol. Sci. Med. Sci. 2017, 73, 131-138. [CrossRef]

15. Dusso, A.S.; Brown, A.J.; Slatopolsky, E. Vitamin D. Am. J. Physiol. Renal Physiol. 2005, 289, F8-F28. [CrossRef]

16. Bikle, D.D.; Gee, E.; Halloran, B.; Kowalski, M.A.; Ryzen, E.; Haddad, J.G. Assessment of the free fraction of 25-hydroxyvitamin D in serum and its regulation by albumin and the vitamin D-binding protein. J. Clin. Endocrinol. Metab. 1986, 63, 954-959. [CrossRef]

17. Brown, A.J.; Coyne, D.W. Bioavailable vitamin D in chronic kidney disease. Kidney Int. 2012, 82, 5-7. [CrossRef]

18. Yousefzadeh, P.; Shapses, S.A.; Wang, X. Vitamin D Binding Protein Impact on 25-Hydroxyvitamin D Levels under Different Physiologic and Pathologic Conditions. Int. J. Endocrinol. 2014, 2014, 98158. [CrossRef]

19. Bhan, I.; Powe, C.E.; Berg, A.H.; Ankers, E.; Wenger, J.B.; Karumanchi, S.A.; Thadhani, R.I. Bioavailable vitamin D is more tightly linked to mineral metabolism than total vitamin D in incident hemodialysis patients. Kidney Int. 2012, 82, 84-89. [CrossRef]

20. Lowe, N.M.; Mitra, S.R.; Foster, P.C.; Bhojani, I.; McCann, J.F. Vitamin D status and markers of bone turnover in Caucasian and South Asian postmenopausal women living in the UK. Br. J. Nutr. 2010, 103, 1706-1710. [CrossRef]

21. Powe, C.E.; Ricciardi, C.; Berg, A.H.; Erdenesanaa, D.; Collerone, G.; Ankers, E.; Wenger, J.; Karumanchi, S.A.; Thadhani, R.; Bhan, I. Vitamin D-binding protein modifies the vitamin D-bone mineral density relationship. J. Bone Miner. Res. 2011, 26, 1609-1616. [CrossRef] [PubMed]

22. WHO Expert Consultation. Appropriate body-mass index for Asian populations and its implications for policy and intervention strategies. The Lancet 2004, 363, 157-163.

23. World Health Organization (WHO). Waist Circumference and Waist-Hip Ratio. In Report of WHO Expert Consultation; World Health Organization: Geneva, Switzerland, 2008. 
24. Ilich, J.Z.; Kelly, O.J.; Inglis, J.E. Osteosarcopenic Obesity Syndrome: What Is It and How Can It Be Identified and Diagnosed? Curr. Gerontol. Geriatr. Res. 2016, 2016, 7325973. [CrossRef] [PubMed]

25. Chen, L.K.; Liu, L.K.; Woo, J.; Assantachai, P.; Auyeung, T.W.; Bahyah, K.S.; Chou, M.; Chen, L.; Hsu, P.; Krairit, O.; et al. Sarcopenia in Asia: Consensus report of the Asian Working Group for Sarcopenia. J. Am. Med. Dir. Assoc. 2014, $15,95-101$. [CrossRef] [PubMed]

26. Johansen, A.; Evans, W.; Stone, M. Bone assessment in elderly women: What does a low bone ultrasound result tell us about bone mineral density? Arch. Gerontol. Geriatr. 1999, 28, 239-246. [CrossRef]

27. Institute of Medicine. Dietary Reference Intakes for Calcium and Vitamin, D; The National Academic Press USA of Medicine: Washington, DC, USA, 2011.

28. Powe, C.E.; Seely, E.W.; Rana, S.; Bhan, I.; Ecker, J.; Karumanchi, S.A.; Thadhani, R. First trimester vitamin D, vitamin D binding protein, and subsequent preeclampsia. Hypertension 2010, 56, 758-763. [CrossRef]

29. Sai, A.J.; Walters, R.W.; Fang, X.; Gallagher, J.C. Relationship between vitamin D, parathyroid hormone, and bone health. J. Clin. Endocrinol. Metab. 2011, 96, E436-E446. [CrossRef]

30. Rosen, C.J.; Abrams, S.A.; Aloia, J.F.; Brannon, P.M.; Clinton, S.K.; Durazo-Arvizu, R.A.; Gallagher, J.C.; Gallo, R.L.; Jones, G.; Kovacs, C.S.; et al. IOM committee members respond to Endocrine Society vitamin D guideline. J. Clin. Endocrinol. Metab. 2012, 97, 1146-1152. [CrossRef]

31. Matchar, D.B.; Chei, C.L.; Yin, Z.X.; Koh, V.; Chakraborty, B.; Shi, X.M.; Zeng, Y. Vitamin D Levels and the Risk of Cognitive Decline in Chinese Elderly People: The Chinese Longitudinal Healthy Longevity Survey. J. Gerontol. A Biol. Sci. Med. Sci. 2016, 71, 1363-1368. [CrossRef]

32. Bischoff-Ferrari, H.A.; Can, U.; Staehelin, H.B.; Platz, A.; Henschkowski, J.; Michel, B.A.; Dawson-Hughes, B.; Theiler, R. Severe vitamin D deficiency in Swiss hip fracture patients. Bone 2008, 42, 597-602. [CrossRef]

33. Thambiah, S.C.; Wong, T.H.; Gupta, E.D.; Radhakrishnan, A.K.; Gun, S.C.; Chembalingam, G.; Yeap, S.S. Calculation of free and bioavailable vitamin D and its association with bone mineral density in Malaysian women. Malays. J. Pathol. 2018, 40, 287-294. [PubMed]

34. Steingrimsdottir, L.; Gunnarsson, O.; Indridason, O.S.; Franzson, L.; Sigurdsson, G. Relationship between serum parathyroid hormone levels, vitamin D sufficiency, and calcium intake. JAMA 2005, 294, 2336-2341. [CrossRef] [PubMed]

35. Souberbielle, J.C.; Cormier, C.; Kindermans, C.; Gao, P.; Cantor, T.; Forette, F.; Baulieu, E.E. Vitamin D status and redefining serum parathyroid hormone reference range in the elderly. J. Clin. Endocrinol. Metab. 2001, 86, 3086-3090. [CrossRef]

36. Shafinaz, I.S.; Moy, F.M. Vitamin D level and its association with adiposity among multi-ethnic adults in Kuala Lumpur, Malaysia: A cross sectional study. BMC Public Health. 2016, 16, 232. [CrossRef]

37. Lavie, C.J.; DiNicolantonio, J.J.; Milani, R.V.; O'Keefe, J.H. Vitamin D and Cardiovascular Health. Circulation 2013, 128, 2404-2406. [CrossRef]

38. Lips, P. Vitamin D status and nutrition in Europe and Asia. J. Steroid. Biochem. Mol. Biol. 2007, 103, 620-625. [CrossRef]

39. Moy, F.M.; Bulgiba, A. High prevalence of vitamin D insufficiency and its association with obesity and metabolic syndrome among Malay adults in Kuala Lumpur, Malaysia. BMC Public Health. 2011, 11, 735. [CrossRef]

40. Valcour, A.; Zierold, C.; Podgorski, A.L.; Olson, G.T.; Wall, J.V.; DeLuca, H.F.; Bonelli, F. A novel, fully-automated, chemiluminescent assay for the detection of 1,25-dihydroxyvitamin D in biological samples. J. Steroid. Biochem. Mol. Biol. 2016, 164, 120-126. [CrossRef]

41. Nurbazlin, M.; Chee, W.S.; Rokiah, P.; Tan, A.T.; Chew, Y.Y.; Nusaibah, A.R.; Chan, S.P. Effects of sun exposure on 25(OH) vitamin D concentration in urban and rural women in Malaysia. Asia Pac. J. Clin. Nutr. 2013, 22, 391-399.

42. Rahman, S.A.; Chee, W.S.; Yassin, Z.; Chan, SP. Vitamin D status among postmenopausal Malaysian women. Asia Pac. J. Clin. Nutr. 2004, 13, 255-260.

43. Sng, J.; Koh, D.; Siong, W.C.; Choo, T.B. Skin cancer trends among Asians living in Singapore from 1968 to 2006. J. Am. Acad. Dermatol. 2009, 61, 426-432. [CrossRef] [PubMed]

44. Tsiaras, W.G.; Weinstock, M.A. Factors influencing vitamin D status. Acta Derm. Venereol. 2011, 91, 115-124. [CrossRef] [PubMed]

45. Li, C.; Chen, P.; Duan, X.; Wang, J.; Shu, B.; Li, X.; Ba, Q.; Li, J.; Wang, Y.; Wang, H. Bioavailable 25(OH)D but Not Total 25(OH)D Is an Independent Determinant for Bone Mineral Density in Chinese Postmenopausal Women. EBioMedicine 2017, 15, 184-192. [CrossRef] [PubMed]

46. Bischoff-Ferrari, H.A.; Dietrich, T.; Orav, E.J.; Hu, F.B.; Zhang, Y.; Karlson, E.W.; Dawson-Hughes, B. Higher 25-hydroxyvitamin D concentrations are associated with better lower-extremity function in both active and inactive persons aged $>$ or $=60 \mathrm{y} . A m$. $\mathrm{J}$. Clin. Nutr. 2004, 80, 752-758. [CrossRef] [PubMed]

47. Heaney, RP. Effects of caffeine on bone and the calcium economy. Food Chem. Toxicol. 2002, 40, 1263-1270. [CrossRef]

48. Holick, M.F.; Chen, T.C. Vitamin D deficiency: A worldwide problem with health consequences. Am. J. Clin. Nutr. 2008, 87, 1080s-1086s. [CrossRef]

49. Johnsen, M.S.; Grimnes, G.; Figenschau, Y.; Torjesen, P.A.; Almås, B.; Jorde, R. Serum free and bio-available 25-hydroxyvitamin D correlate better with bone density than serum total 25-hydroxyvitamin D. Scand. J. Clin. Lab. Investig. 2014, 74, 177-183. [CrossRef]

50. Aloia, J.F. African Americans, 25-hydroxyvitamin D, and osteoporosis: A paradox. Am. J. Clin. Nutr. 2008, 88, 545s-550s. [CrossRef] 
51. Jemielita, T.O.; Leonard, M.B.; Baker, J.; Sayed, S.; Zemel, B.S.; Shults, J.; Herskovitz, R.; Denburg, M.R. Association of 25hydroxyvitamin $\mathrm{D}$ with areal and volumetric measures of bone mineral density and parathyroid hormone: Impact of vitamin D-binding protein and its assays. Osteoporos. Int. 2016, 27, 617-626. [CrossRef]

52. Lim, P.S.; Ong, F.B.; Adeeb, N.; Seri, S.S.; Noor-Aini, M.Y.; Shamsuddin, K.; Hapizah, N.; Mohamed, A.L.; Mokhtar, A.; Wan, H.W.H. Bone health in urban midlife Malaysian women: Risk factors and prevention. Osteoporos Int. 2005, 16, 2069-2079. [CrossRef]

53. Chan, C.Y.; Subramaniam, S.; Mohamed, N.; Ima-Nirwana, S.; Muhammad, N.; Fairus, A.; Ng, P.Y.; Jamil, N.A.; Abd Aziz, N.; Chin, K. Determinants of Bone Health Status in a Multi-Ethnic Population in Klang Valley, Malaysia. Int. J. Environ. Res. Public Health 2020, 17, 384. [CrossRef] [PubMed]

54. Palermo, A.; Tuccinardi, D.; Defeudis, G.; Watanabe, M.; D'Onofrio, L.; Lauria Pantano, A.; Napoli, N.; Pozzilli, P.; Manfrini, S. BMI and BMD: The Potential Interplay between Obesity and Bone Fragility. Int. J. Environ. Res. Public Health 2016, 13, 544. [CrossRef] [PubMed]

55. Ceglia, L.; Harris, S.S. Vitamin D and its role in skeletal muscle. Calcif. Tissue Int. 2013, 92, 151-162. [CrossRef]

56. Girgis, C.M.; Clifton-Bligh, R.J.; Hamrick, M.W.; Holick, M.F.; Gunton, J.E. The roles of vitamin D in skeletal muscle: Form, function, and metabolism. Endocr. Rev. 2013, 34, 33-83. [CrossRef] [PubMed]

57. Ko, M.J.; Yun, S.; Oh, K.; Kim, K. Relation of serum 25-hydroxyvitamin D status with skeletal muscle mass by sex and age group among Korean adults. Br. J. Nutr. 2015, 114, 1838-1844. [CrossRef] [PubMed]

58. Visser, M.; Deeg, D.J.; Lips, P. Low vitamin D and high parathyroid hormone levels as determinants of loss of muscle strength and muscle mass (sarcopenia): The Longitudinal Aging Study Amsterdam. J. Clin. Endocrinol. Metab. 2003, 88, 5766-5772. [CrossRef]

59. Abboud, M.; Puglisi, D.A.; Davies, B.N.; Rybchyn, M.; Whitehead, N.P.; Brock, K.E.; Cole, L.; Gordon-Thomson, C.; Fraser, D.R.; Mason, R.S. Evidence for a specific uptake and retention mechanism for 25-hydroxyvitamin D (25OHD) in skeletal muscle cells. Endocrinology 2013, 154, 3022-3030. [CrossRef]

60. Davis, H.G. Conservative Surgery: As Exhibited in Remedying Some of the Mechanical Causes that Operate Injuriously Both in Health and Disease; Illustrations. D. Appleton: Boston, MA, USA, 1867.

61. Ahern, T.; Khattak, A.; O’Malley, E.; Dunlevy, C.; Kilbane, M.; Woods, C.; McKenna, M.J.; O’Shea, D. Association Between Vitamin D Status and Physical Function in the Severely Obese. J. Clin. Endocrinol. Metabo. 2014, 99, E1327-E1331. [CrossRef]

62. Snijder, M.B.; van Schoor, N.M.; Pluijm, S.M.; van Dam, R.M.; Visser, M.; Lips, P. Vitamin D status in relation to one-year risk of recurrent falling in older men and women. J. Clin. Endocrinol. Metab. 2006, 91, 2980-2985. [CrossRef]

63. Wicherts, I.S.; van Schoor, N.M.; Boeke, A.J.; Visser, M.; Deeg, D.J.; Smit, J.; Knol, D.L.; Lips, P. Vitamin D status predicts physical performance and its decline in older persons. J. Clin. Endocrinol. Metab. 2007, 92, 2058-2065. [CrossRef]

64. Vermeulen, A.; Verdonck, L.; Kaufman, J.M. A critical evaluation of simple methods for the estimation of free testosterone in serum. J. Clin. Endocrinol. Metabol. 1999, 84, 3666-3672. [CrossRef]

65. Grampp, S.; Genant, H.K.; Mathur, A.; Lang, P.; Jergas, M.; Takada, M.; Gluer, C.; Lu, Y.; Chavez, M. Comparisons of noninvasive bone mineral measurements in assessing age-related loss, fracture discrimination, and diagnostic classification. J. Bone Miner. Res. 1997, 12, 697-711. [CrossRef] [PubMed]

66. Baumgartner, R.N.; Koehler, K.M.; Gallagher, D.; Romero, L.; Heymsfield, S.B.; Ross, R.R.; Garry, P.J.; Lindeman, R.D. Epidemiology of sarcopenia among the elderly in New Mexico. Am. J. Epidemiol. 1998, 147, 755-763. [CrossRef] [PubMed]

67. Fess, E.E. Grip Strength, 2nd ed.; American Society of Hand Therapists: Chicago, IL, USA, 1992.

68. Guralnik, J.M.; Simonsick, E.M.; Ferrucci, L.; Glynn, R.J.; Berkman, L.F.; Blazer, D.G.; Scherr, P.A.; Wallace, R.B. A short physical performance battery assessing lower extremity function: Association with self-reported disability and prediction of mortality and nursing home admission. J. Gerontol. 1994, 49, M85-M94. [CrossRef] [PubMed]

69. Kim, H.J.; Ji, M.; Song, J.; Moon, H.W.; Hur, M.; Yun, Y.M. Clinical Utility of Measurement of Vitamin D-Binding Protein and Calculation of Bioavailable Vitamin D in Assessment of Vitamin D Status. Ann. Lab. Med. 2017, 37, 34-38. [CrossRef] [PubMed]

70. Heijboer, A.C.; Blankenstein, M.A.; Kema, I.P.; Buijs, M.M. Accuracy of 6 routine 25-hydroxyvitamin D assays: Influence of vitamin D binding protein concentration. Clin. Chem. 2012, 58, 543-548. [CrossRef] [PubMed]

71. Hoaglin, D.C.; Iglewicz, B. Fine-Tuning Some Resistant Rules for Outlier Labeling. J. Am. Stat. Assoc. 1987, 82, 1147-1149. [CrossRef]

72. Rizzoli, R.; Boonen, S.; Brandi, M.L.; Bruyère, O.; Cooper, C.; Kanis, J.A.; Kaufman, J.; Ringe, J.D.; Weryha, G.; Reginster, J. Vitamin D supplementation in elderly or postmenopausal women: A 2013 update of the 2008 recommendations from the European Society for Clinical and Economic Aspects of Osteoporosis and Osteoarthritis (ESCEO). Curr. Med. Res. Opin. 2013, 29, 305-313. [CrossRef]

73. Rizzoli, R.; Stevenson, J.C.; Bauer, J.M.; van Loon, L.J.; Walrand, S.; Kanis, J.A.; Cooper, C.; Brandi, M.; Diez-Perez, A.; Reginster, J.; et al. The role of dietary protein and vitamin D in maintaining musculoskeletal health in postmenopausal women: A consensus statement from the European Society for Clinical and Economic Aspects of Osteoporosis and Osteoarthritis (ESCEO). Maturitas 2014, 79, 122-132. [CrossRef]

74. Nagaraj, S.; Nai-Peng, T.; Chiu-Wan, N.; Kiong-Hock, L.; Pala, J. Counting ethnicity in Malaysia: The complexity of measuring diversity. In Social Statistics and Ethnic Diversity; Springer: Cham, Switzerland, 2015; pp. 143-173.

75. Bouillon, R.; Schuit, F.; Antonio, L.; Rastinejad, F. Vitamin D Binding Protein: A Historic Overview. Front. Endocrinol. 2020, 10, 910. [CrossRef] 